PALABRAS CLAVE

Crisis financiera

Desarrollo económico

Estrategias del desarrollo

Desarrollo sostenible

Macroeconomía

Inversiones

Productividad

Distribución del ingreso

Política social

América Latina

Caribe

Alicia Bárcena

Secretaria Ejecutiva de la Comisión

Económica para América Latina y

el Caribe (CEPAL)

œ alicia.barcena@cepal.org
REVISTA CEPAL 100 - ABRIL 2010

\section{Restricciones estructurales del desarrollo en América Latina y el Caribe: una reflexión postcrisis}

\author{
Alicia Bárcena
}

$\mathrm{E}$

desarrollo de América Latina y el Caribe sigue siendo una tarea inconclusa. Si bien en materia macroeconómica se lograron avances que contribuyeron a enfrentar de mejor manera la reciente crisis, esta ha dejado al descubierto viejas y nuevas restricciones estructurales a los países de la región, que se reflejan en la persistencia de importantes brechas sociales, productivas, fiscales y ambientales. Cerrar estas brechas constituye una exigencia para el bienestar de las generaciones futuras y una condición de viabilidad para un desarrollo en que se combinen crecimiento económico, equidad y sostenibilidad. De allí surge una reflexión más allá de lo puramente económico sobre la necesidad de que el Estado vuelva a desempeñar un papel relevante en las estrategias del desarrollo, de modo que las políticas públicas sean el principal protagonista en la construcción del futuro. El objetivo mayor de este artículo es precisamente el de plantear esa reflexión. 


\section{I}

\section{Introducción}

La CEPAL ha planteado tres hipótesis generales sobre la caracterización y consecuencias de la reciente crisis. La primera hipótesis es que ella no constituye solo la expresión de una debilidad regulatoria de los sistemas financieros, ni el exclusivo resultado de una crisis moral provocada por la ambición y la avaricia. La crisis también pone fin a "un estilo de desarrollo" y abre nuevos senderos para el debate económico, social y ambiental.

La segunda hipótesis es que el Estado debe volver a jugar un papel en la conducción de las estrategias de desarrollo de los países de la región. A partir de una mirada crítica sobre el desempeño reciente del Estado, es imprescindible redefinir su papel y sus formas de funcionamiento, con el fin de lograr una equilibrada interacción entre el mercado, las instituciones y el ciudadano en el proceso del desarrollo.

La tercera hipótesis se desprende con naturalidad de las anteriores, y atañe a la necesidad de recuperar la idea de construir una estrategia de desarrollo de "largo plazo". Para ello se debe acrecentar la capacidad de proponer e implementar medidas de política pública que hagan coherente lo urgente con lo importante.

Pese a los avances alcanzados en la última década, el desarrollo económico y social de América Latina y el Caribe sigue siendo una tarea inconclusa. En el campo de la macroeconomía se han verificado importantes avances que se traducen en una mejor situación fiscal, menores tasas de inflación y menores niveles de deuda externa, factores todos que contribuyeron a enfrentar de mejor manera la crisis económica y financiera global que se inició en 2008. Pero al mismo tiempo, las sucesivas perturbaciones (shocks) financieras ocurridas desde los años noventa han redundado en una mayor volatilidad del ciclo económico y en un patrón de crecimiento insatisfactorio. Viejos problemas como la dinámica de la productividad, la heterogeneidad productiva y la creación y difusión de capacidades tecnológicas siguen persistiendo y enmarcan algunas de las restricciones estructurales que enfrenta la región. De este modo, si bien la crisis reciente nos enseña la importancia de fortalecer

$\square$ La autora desea agradecer la colaboración de Mario Cimoli, Filipa Correia y Daniel Titelman, así como las contribuciones de Osvaldo Kacef, Joseluis Samaniego y Luis Yáñez. la capacidad contracíclica de las políticas macroeconómicas, también nos recuerda la necesidad de priorizar las políticas productivas y ampliar la cobertura y mejorar el diseño de las políticas sociales. Esto confirma la necesidad de reconstruir aquellas capacidades del Estado que le permitan recuperar la planificación estratégica de políticas de largo plazo, ampliar los espacios para la política fiscal y diseñar instrumentos adecuados para afrontar los desafíos estructurales que pesan sobre el actual patrón de desarrollo de la región.

En este artículo se propone una reflexión sobre las políticas y la acción del Estado en América Latina y el Caribe. Se argumenta en favor de nuevas formas de intervención y gestión de las políticas, sin las cuales no sería posible avanzar hacia los diversos objetivos de un patrón de desarrollo, con crecimiento, equidad y sostenibilidad. Al mismo tiempo, se arguye en favor de un nuevo debate y de la centralidad de la política para redefinir los espacios del Estado y el mercado, de tal manera que las exigencias del desarrollo avancen de modo compatible con la ampliación de los derechos de ciudadanía y de las instituciones democráticas.

El presente artículo se estructura como sigue. En la sección II se presenta un breve recorrido del desempeño macroeconómico de América Latina y el Caribe, donde se debaten su relación con la dependencia externa y los problemas estructurales que la han aquejado históricamente. En la sección III se complementa el análisis con las tendencias que se han registrado paralelamente en el panorama social regional. Los mecanismos de transmisión y los efectos de la crisis en la región se analizan en la sección IV, así como las respuestas por parte de los países latinoamericanos y caribeños. En la sección V se presenta el escenario postcrisis y se discuten los viejos y los nuevos problemas estructurales ya señalados por la tradición del pensamiento cepalino. Estos se reflejan en la persistencia de importantes brechas en lo social (pobreza, exclusión y desigual distribución del ingreso), en lo productivo (inversión, productividad e innovación), en lo fiscal (nivel y eficiencia del gasto y recaudación fiscal) y en lo ambiental (producción baja en carbono y eficiencia energética). Se señala que esto último no es solo una condición de viabilidad del crecimiento y el bienestar de las generaciones futuras, sino también, cada vez más, una exigencia de la "nueva 
normalidad" internacional que se viene diseñando, en la que surgen restricciones vinculadas al contenido de carbono de los bienes. Tales restricciones tendrán una repercusión sustancial en el comercio internacional y en las formas de inserción de América Latina y el Caribe en la postcrisis.

\section{II}

\section{Hechos estilizados del desempeño}

\section{macroeconómico}

En el plano macroeconómico la región se caracteriza por un bajo y volátil crecimiento, sobre todo a partir de los años ochenta, que ha redundado en la persistencia de una significativa brecha entre los niveles del producto interno bruto (PIB) per cápita de América Latina y el Caribe y los de los países desarrollados.

Luego de una expansión del PIB cercana al $6 \%$ en los años setenta, en los años ochenta (la "década perdida") el crecimiento económico se redujo a un $2 \%$, y en la década de 1990 se situó en un 3\%. La "década perdida" estuvo signada por bajas tasas de crecimiento e inversión, vinculadas al enorme esfuerzo de pago de la deuda contraída en los años setenta. A ello se sumó una aguda inestabilidad macroeconómica, en la que se destacaban niveles muy elevados de inflación, que en algunos países llegaron a generar episodios de hiperinflación, desestructurando fuertemente la economía y agravando los problemas de pobreza e inequidad. En lo concerniente a la política económica, el objetivo primordial era reducir los niveles de inflación, por lo que predominaron las preocupaciones de corto plazo (CEPAL, 2002). Además, durante los años ochenta la región no solo enfrentó una marcada caída de la tasa de crecimiento del producto, también se vio afectada en términos de las condiciones sociales y experimentó un pronunciado rezago frente a una frontera tecnológica en rápido movimiento. De este modo, América Latina y el Caribe llega a los años noventa más débil, sin incremento de productividad, sin difusión de las innovaciones tecnológicas y sin expansión de las capacidades productivas.

La década de 1990 comienza con señales más favorables en el ámbito internacional, con el llamado Plan Brady (1989), que facilitó el retorno a los mercados financieros internacionales. Este contexto más propicio tuvo un papel significativo en el éxito de los planes más audaces de estabilización que se adoptaron en los años noventa, acentuando medidas de liberalización de la economía, incluida entre estas la apertura comercial.
A medida que avanzaban los años noventa hubo conquistas clave en el plano macroeconómico que no deben dejarse de lado, en particular el éxito que las economías latinoamericanas y caribeñas lograron al evitar nuevos desbordes inflacionarios o mayores descontroles fiscales en general. Estos fueron aspectos positivos de la administración de las políticas macroeconómicas; sin embargo, algunos de sus efectos colaterales no recibieron la necesaria atención, en especial aquellos relativos a la atracción del capital externo de corto plazo.

A pesar de los éxitos logrados en el combate a la inflación, no hubo una notoria recuperación del crecimiento. La estabilidad tampoco se logró completamente, ya que el período se caracterizó por una secuencia de crisis externas que se volvieron más recurrentes y contagiosas hacia el final de la década. Se destacan la crisis mexicana en diciembre de 1994, la asiática de 1998, la brasileña a comienzos de 1999 y la argentina de 2000-2001. Las diversas crisis redundaron en un pronunciado retroceso en el ritmo de crecimiento y en un aumento de la volatilidad. Este período de estancamiento (visto desde la perspectiva del crecimiento) se cierra con un quinquenio de notable crecimiento económico (2003-2008), que corresponde a la bonanza ligada al mejoramiento de los precios de los productos básicos (commodities) y al fuerte impulso expansivo que logra la economía mundial.

Tanto en la década de 1980 como en los años noventa, los países de América Latina y el Caribe han tendido a seguir políticas procíclicas, que amplifican las fases de alta y de baja a lo largo del ciclo del crecimiento (Ffrench-Davis, 2005). Tales políticas han acompañado pasivamente a los momentos de abundancia y retracción de la oferta de capitales, permitiendo fases de endeudamiento exagerado aparejadas con la valorización de sus monedas, seguidas por contracciones intensas y agudas desvalorizaciones (Stiglitz y otros, 2006). Todo ello repercute negativamente en el crecimiento, la estabilidad y la propia construcción de capacidades tecnológicas y 
productivas, que necesariamente se ven afectados al tener que ajustarse a fluctuaciones frecuentes en los precios relativos y en los niveles de demanda y producción. En particular, el énfasis en la obtención de equilibrios presupuestales y en el uso de instrumentos de control de la inflación (sobre todo de la tasa de interés), sin considerar al mismo tiempo sus efectos en el tipo de cambio (y la competitividad), ha contribuido a generar un salto en las importaciones y una menor densidad de la matriz de insumo-producto de las economías latinoamericanas. Este cuadro de debilidad de la estructura productiva implica que los efectos de arrastre de las exportaciones al resto de la economía son poco profundos, a lo que se suma una mayor vulnerabilidad ante una reversión de la fase favorable en el frente externo (Ocampo, 2005).

A partir de 2002 y hasta el estallido de la actual crisis, América Latina y el Caribe fue capaz de retomar tasas de crecimiento similares a las de los años setenta. Efectivamente, el período 2003-2007 fue un período de bonanza que se reflejó en un elevado crecimiento del PIB en torno del 5\%, mientras que el PIB per cápita de la región sobrepasó el 3\% por casi cinco años consecutivos, en un contexto de saldos positivos de cuenta corriente, superávit fiscal y una acumulación de reservas internacionales sin precedentes (véase el gráfico 1). Al mismo tiempo, el desempleo registró una marcada disminución (del $11 \%$ al $7,4 \%$ ) y el porcentaje de personas bajo la línea de la pobreza se redujo en 10 puntos porcentuales (del 44\% al 34\%). Esta combinación tan favorecedora de alto crecimiento en conjunto con una holgada situación externa era inédita en la experiencia histórica reciente de la región (CEPAL, 2009a).

Un factor clave en la obtención de estos resultados tan favorables fue el crecimiento de la economía mundial, que bordeó el 3,6\% anual durante el período 2003-2008 (DESA, 2010). Esto se tradujo en una expansión del comercio internacional en la región, que registró un crecimiento del $138 \%$ en valor, y en un sostenido incremento en los términos del intercambio, que aumentaron un $25 \%$ en el mismo periodo. La expansión económica de Asia, y sobre todo de China, que en promedio creció al $11 \%$ anual en el mismo período, fue decisiva para

GRÁFICO 1

América Latina y el Caribe: tasa de variación del PIB per cápita y saldo en cuenta corriente y resultado fiscal global

(En tasas de variación anual y porcentajes del PIB)

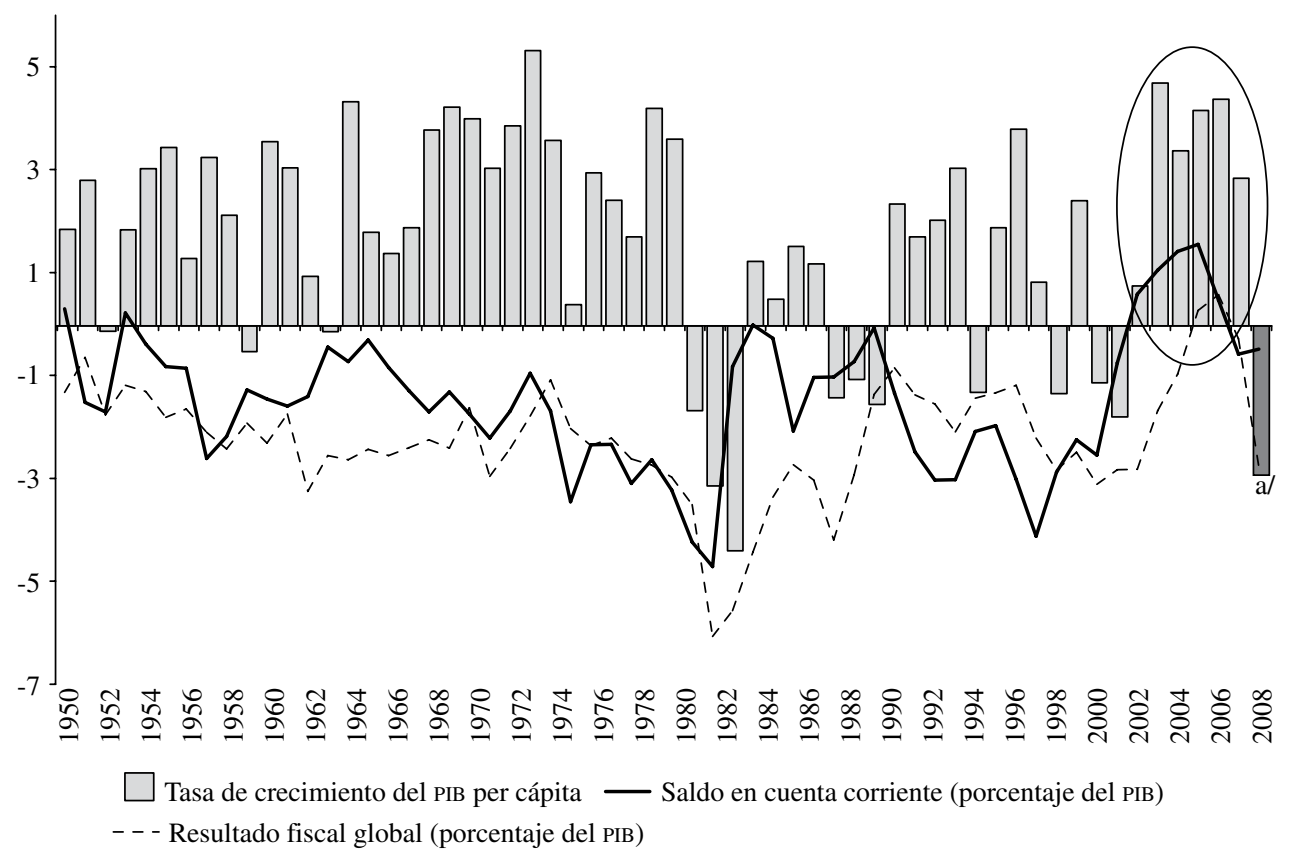

Fuente: Comisión Económica para América Latina y el Caribe (CEPAL), sobre la base de cifras oficiales.

a Proyección para 2009.

PIB: Producto interno bruto. 
este mejor desempeño de la economía mundial, con fuertes repercusiones en América Latina y el Caribe (Rosales, 2009). Mientras tanto, el nuevo papel de los países asiáticos en la economía internacional tiene una doble dimensión que no debe olvidarse. Si bien estos países representan un gran competidor para la región en algunas ramas manufactureras, son al mismo tiempo una fuerza que promueve la expansión del comercio de materias primas que la región exporta. Este doble efecto conlleva que el impacto de Asia sea distinto según la especialización internacional de los países. Por una parte, los grandes exportadores de commodities basados en recursos naturales se han beneficiado sustancialmente de la demanda asiática y del mejoramiento en los términos del intercambio. En América del Sur, donde residen la mayor parte de los exportadores de productos básicos, los términos del intercambio registraron un aumento del $33 \%$ en este período. Inversamente, aquellos países que exportan bienes intensivos en trabajo, como México, y que además no son ricos en recursos naturales (como muchas de las economías centroamericanas y del Caribe), han sufrido notoriamente la competencia china y han visto reducirse sus espacios. A su vez, países que exportan bienes de baja y media tecnología, como el Brasil, han quedado en una situación intermediaria, aunque hay evidencias de que son cada vez más afectados a medida que China diversifica sus exportaciones hacia bienes más intensivos en tecnología (CEPAL, 2009b; CEPAL, 2009f).

A diferencia de otros períodos, el comprendido entre 2002 y 2008 se distingue por una administración prudente del shock externo favorable y por políticas macro que permitieron alcanzar positivos resultados fiscales, la acumulación de activos externos para enfrentar contingencias, bajas tasas de desempleo e inflación, y el fortalecimiento de los sistemas financieros domésticos (CEPAL, 2008b).

\section{III}

\section{Tendencias y cambios en el panorama social}

Los ciclos de crecimiento y estabilidad tienen una contrapartida social. Esta contrapartida es especialmente importante en América Latina y el Caribe, que se ha caracterizado históricamente por mantener elevados niveles de desigualdad. Como se desprende del gráfico 2, la evolución de la pobreza tiene el formato de una parábola que de cierta forma reproduce las fases de crecimiento. De esa manera, la pobreza aumenta a partir de los años ochenta hasta el inicio de los noventa, decreciendo posteriormente, con lo que la incidencia de la pobreza cae del $48 \%$ al $33 \%$ entre 1990 y 2008.

GRÁFICO 2

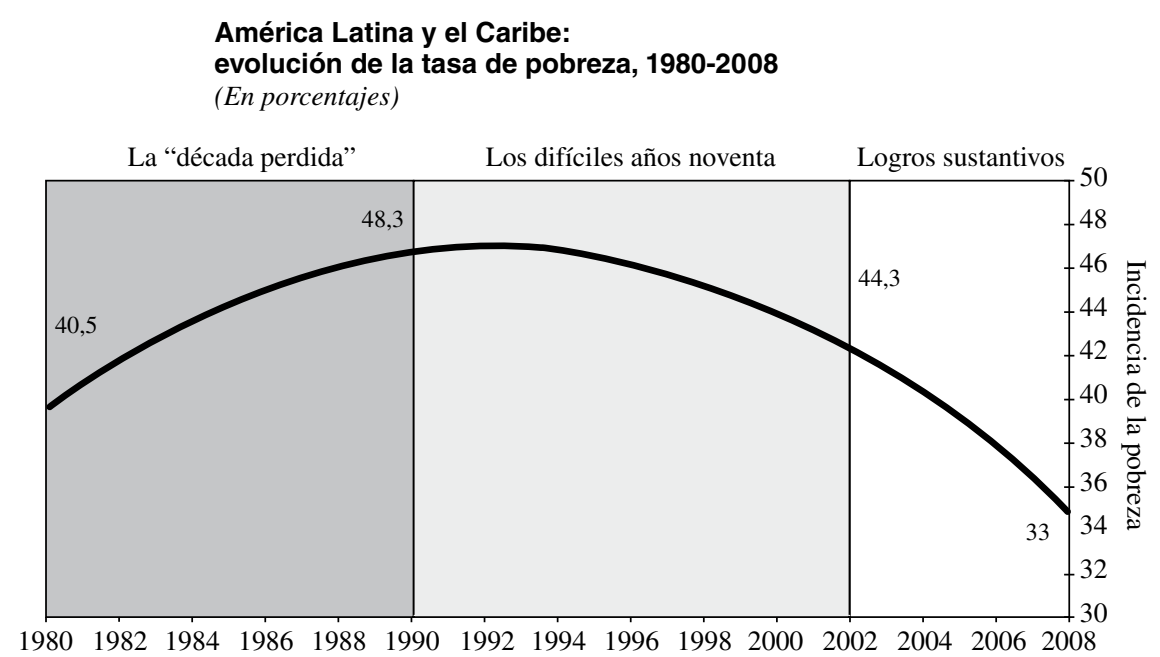

Fuente: Comisión Económica para América Latina y el Caribe (CEPAL), sobre la base de cifras oficiales. 
Durante la "década perdida" de los años ochenta la falta de crecimiento y las políticas de restricción fiscal (que repercutían negativamente en el gasto social) derivaron en los más altos niveles de pobreza en la región. Desde fines de los años ochenta e inicio de los noventa, a medida que se registraron mejoras en el crecimiento y el empleo y se profundizaron las políticas sociales, se revirtió la tendencia al incremento de la pobreza y esta comenzó a retroceder. En los últimos años se han visto relevantes avances en el ámbito social en América Latina y el Caribe, mejorando el cuadro ostensiblemente negativo heredado de la "década perdida". Ya a partir de 2002, el crecimiento sostenido y la extensión en mayor escala de las políticas sociales permitieron alcanzar el punto más bajo de pobreza de los últimos 30 años (CEPAL, 2009d).

El año 2008 fue el último de un sexenio caracterizado por la creciente reducción de la pobreza y la desigualdad.
Es importante mencionar que a pesar de todos los avances logrados desde finales de los años ochenta, aún hay un largo camino por recorrer. En efecto, el número de personas pobres e indigentes de 2008 supera al de 1980 en 44 millones y 9 millones, respectivamente. Al finalizar el año 2008, aún existían 180 millones de pobres en América Latina, cifra lo suficientemente alta como para alertar sobre la necesidad de profundizar las políticas dirigidas prioritariamente a este sector de la población.

La evaluación del sexenio completo, incluidos los resultados de 2008 para los países con información disponible, arroja un balance final positivo en la lucha contra la pobreza. Como se observa en el gráfico 3, en lo que respecta a la tasa de pobreza, por primera vez todos los países de la región presentaron un valor menor al registrado en torno de 2002. El porcentaje de disminución anual alcanzó sus valores más significativos en Argentina,

GRÁFICO 3

América Latina y el Caribe: variación anual

de las tasas de pobreza e indigencia, 2002-2008

(En porcentajes)

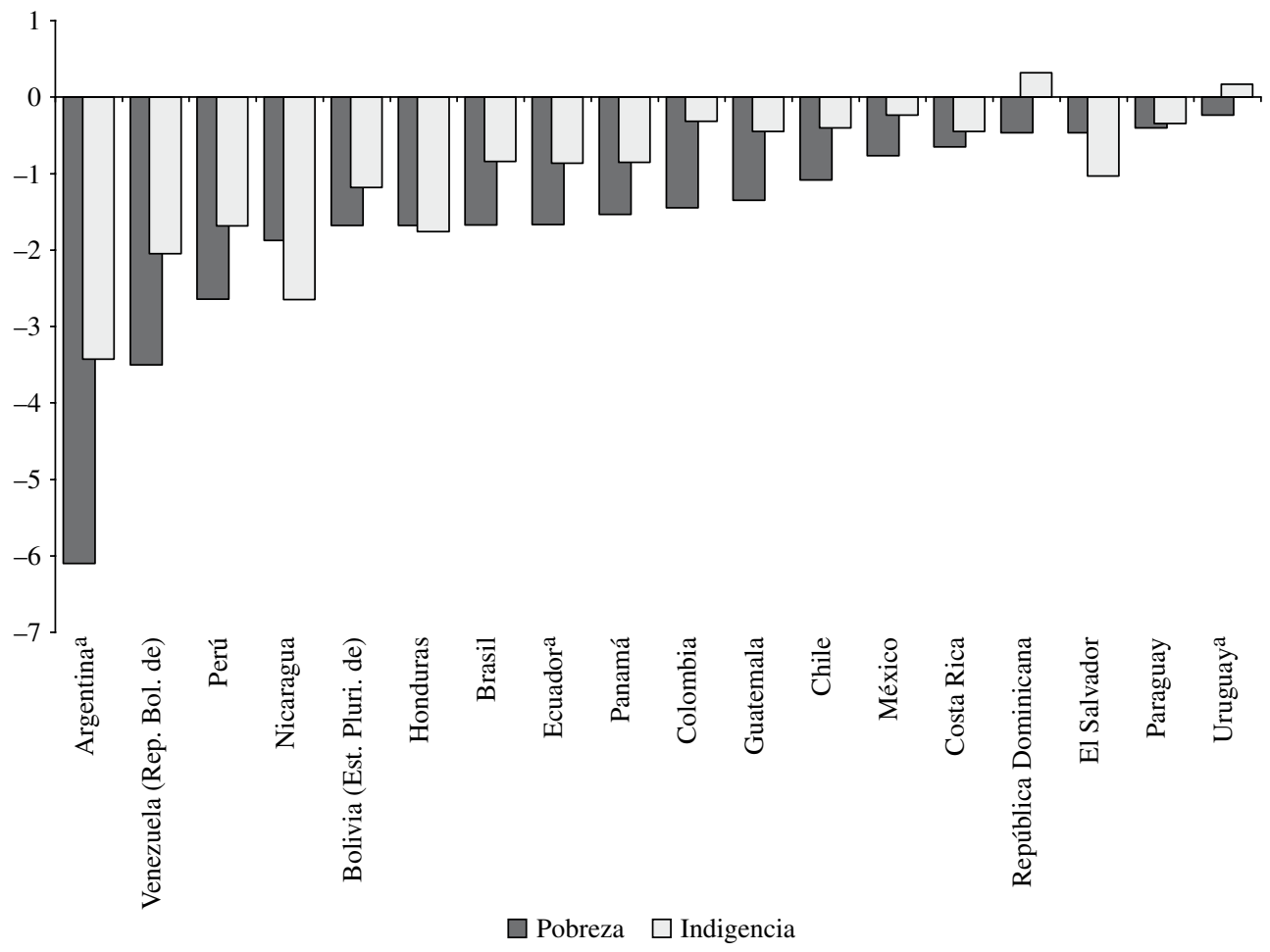

Fuente: Comisión Económica para América Latina y el Caribe (CEPAL), sobre la base de tabulaciones especiales de las encuestas de hogares de los respectivos países.

a Área urbana. 
República Bolivariana de Venezuela, Perú, Nicaragua, Estado Plurinacional de Bolivia, Honduras y Brasil, mientras que en otro extremo se registraron menores reducciones en República Dominicana, El Salvador, Paraguay y Uruguay.

La tasa de indigencia también cayó en todos los países, salvo en República Dominicana y Uruguay. Si bien las reducciones en las tasas de indigencia representan generalmente menos puntos porcentuales que las de la tasa de pobreza, sucede lo contrario al comparar sus variaciones relativas, mostrando que la mejora en las condiciones de vida se produjo especialmente entre quienes se encontraban en la parte más baja de la distribución del ingreso, a pesar del encarecimiento de los alimentos durante el último año.

En materia de inequidad, entre 2002 y 2008 el índice de Gini presentó caídas importantes en varios países, entre los que se destacan República Bolivariana de Venezuela (-18\%), Argentina (-10\%), Perú (-9\%), el Estado Plurinacional de Bolivia, Nicaragua, Panamá y Paraguay ( $-8 \%$ en todos ellos). Los únicos países que registraron incrementos en la concentración del ingreso en este período son Colombia, Guatemala y República Dominicana. Cabe destacar que los datos de Colombia datan de 2005 y los de Guatemala de 2006, por lo que pueden no ser representativos del período 2002-2008 (véase el gráfico 4).

La combinación de mejoras distributivas con el incremento en el ingreso medio de los hogares contribuyó de manera considerable a la reducción de la inequidad, lo que se refleja en una contracción del coeficiente de Gini de 0,55 a 0,52. Esta merma de la desigualdad no es modesta (aunque todavía lejana de niveles de desigualdad aceptables) y en algunos países es muy importante

GRÁFICO 4

América Latina y el Caribe (18 países):

coeficiente de Gini, alrededor de 2002 y 2008

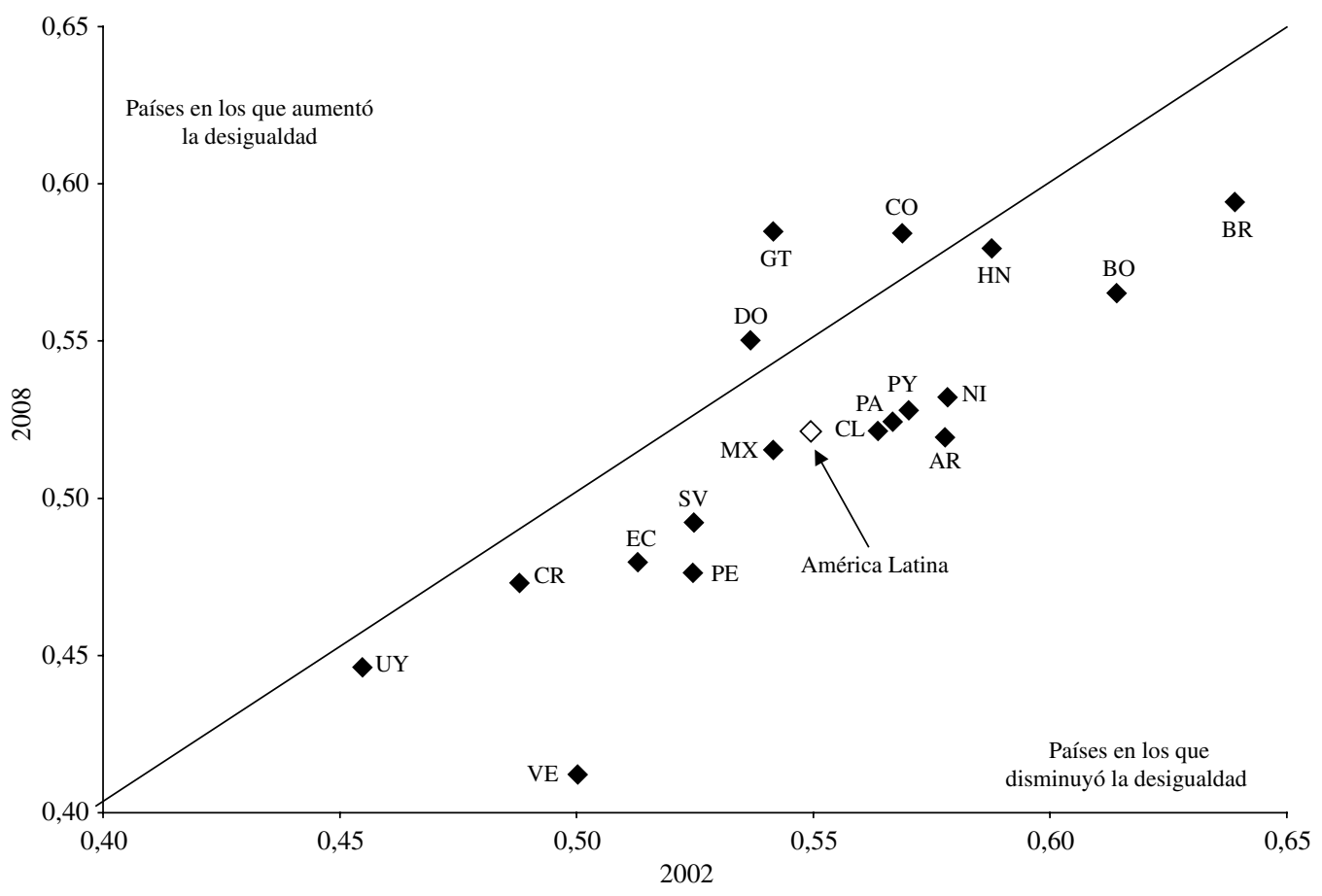

Fuente: Comisión Económica para América Latina y el Caribe (CEPAL), sobre la base de tabulaciones especiales de las encuestas de hogares de los respectivos países.

BR: Brasil. BO: Estado Plurinacional de Bolivia. HN: Honduras. NI: Nicaragua. CO: Colombia. PY: Paraguay. AR: Argentina. PA: Panamá. GT: Guatemala. CL: Chile. MX: México. RD: República Dominicana. SV: El Salvador. PE: Perú. EC: Ecuador. CR: Costa Rica. UY: Uruguay. VE: República Bolivariana de Venezuela. 
(como en Brasil, Argentina, el Estado Plurinacional de Bolivia, Perú y República Bolivariana de Venezuela). Debe recordarse que un rango de variación razonable para el índice de Gini en un período de 10 años oscila entre el 5\% y el 10\%. En el caso de América Latina y el Caribe la caída fue de $3 \%$ en el promedio de los países en seis años, llegando a más de $5 \%$ en algunos de ellos, lo que representa variaciones muy relevantes sobre todo en una región donde tradicionalmente ha sido muy difícil reducir la inequidad (CEPAL, 2009d).

En resumen, en el tercer trimestre del año 2008, América Latina y el Caribe cerró un ciclo de expansión económica (2002-2008) en que se evidenciaron mejoramientos sustantivos y consistentes en los niveles de pobreza (que retroceden del $44 \%$ al $33 \%$ ) y de indigencia (que bajan del 19,4\% al 12,9\%), en la tasa de empleo (que aumenta del 52\% al 55\%) y, en muchos casos, en los niveles de equidad (contracción del coeficiente de
Gini de 0,55 a 0,52 ). A pesar de que hay diferencias entre países, puede afirmarse que las mejoras se observan en casi todos ellos. Estos avances son dignos de destacarse, especialmente a la luz de la trayectoria anterior de las economías latinoamericanas, en las que la desigualdad constituía un desafío particularmente difícil de corregir.

A pesar de las tendencias claramente favorables, debe tenerse presente que los resultados del último sexenio no alteran el hecho de que la desigualdad en América Latina y el Caribe continúa siendo una de las más altas del mundo. Si bien mejoró en la región, no tanto como lo ha hecho en otras regiones en desarrollo, el número absoluto de personas en condiciones de pobreza o indigencia permanece muy elevado. Todo ello implica que en los próximos años los gobiernos no deberían bajar la guardia en el combate a los problemas sociales que aún constituyen un grave obstáculo para el desarrollo latinoamericano.

\section{IV}

\section{La crisis actual, mecanismos de transmisión y respuesta}

A pesar de que en la región se enfrentó la crisis económica en mejor situación macroeconómica que en crisis anteriores (con un marcado crecimiento, acumulación de reservas internacionales, mejor situación fiscal, bajas tasas de desempleo e inflación y sistemas financieros relativamente sólidos), la magnitud de la actual crisis implicó importantes efectos negativos en los países de la región.

La caída del PIB en $2009(-1,8 \%)$ es la mayor desde la crisis de la deuda externa de 1982-1983 (con la excepción de un pequeño retroceso en 2002, esta es la primera vez que la tasa de crecimiento del PIB fue negativa desde 1983). Como se aprecia en el gráfico 5 , la pérdida de dinamismo en el crecimiento ha sido mayor en esta crisis que en crisis anteriores: en la actual se pasó de un crecimiento promedio de $4,8 \%$ a un descenso de $1,8 \%$, lo que implica una pérdida de dinamismo de casi 7 puntos porcentuales en el crecimiento del PIB. En la crisis asiática esta pérdida fue de 4 puntos porcentuales, y en la del "tequila" de 1,6 puntos porcentuales (Pineda, Pérez-Caldentey y Titelman, 2009).

Tradicionalmente, los efectos de las crisis financieras se relacionan con un deterioro significativo de las condiciones externas. En la crisis actual destaca la relevancia del canal comercial, aunque también hubo una caída significativa en el financiamiento externo.

Los flujos financieros netos, sin la inversión extranjera directa, para seis de los principales países de la región pasaron de un $1 \%$ del PIB en el tercer trimestre de 2008 a $-1,5 \%$ del PIB en el segundo trimestre de 2009. ${ }^{1}$ El saldo regional de la balanza financiera, incluidos errores y omisiones, pasó de 64.413 millones de dólares en 2008 a cerca de 53.000 millones de dólares en 2009. La restricción al financiamiento externo ha redundado en una contracción en el crédito doméstico (que se situaba en el 18\% en enero de 2008, disminuyendo a un $2 \%$ en septiembre de 2009).

Pese a la restricción de los flujos financieros, el canal comercial ha sido más importante. La crisis provocó una significativa interrupción de los flujos comerciales. En 2009 se estima un descenso de las exportaciones del $24 \%$ y de las importaciones del 25\% (CEPAL, 2009b; 2009g). Estas cifras se relacionaron también con una merma de la inversión extranjera directa (IED), de las remesas y de los precios de los commodities (véase el gráfico 6) (CEPAL, 2009h; Orozco, 2009).

\footnotetext{
${ }^{1}$ Los seis países considerados son Argentina, Brasil, Chile, Colombia, México y Perú.
} 
GRÁFICO 5

\section{América Latina y el Caribe: crecimiento del PIB}

antes y durante episodios de crisis

(Tasas de crecimiento promedio previo a y durante la crisis)

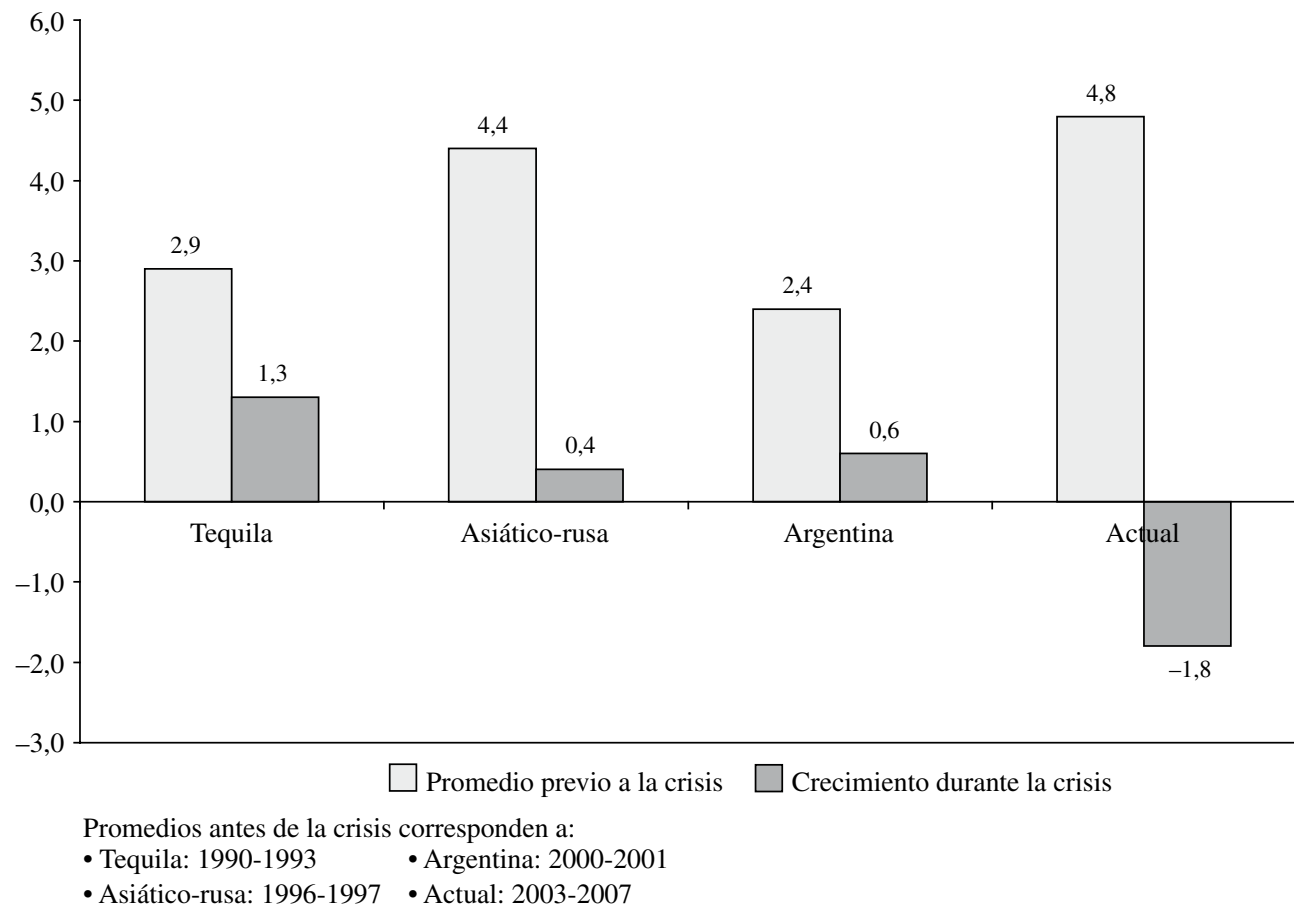

Fuente: Comisión Económica para América Latina y el Caribe (CEPAL), sobre la base de cifras oficiales.

GRÁFICO 6

\section{América Latina y el Caribe: \\ canales de transmisión de la crisis \\ (Tasas de variación anual en porcentajes)}

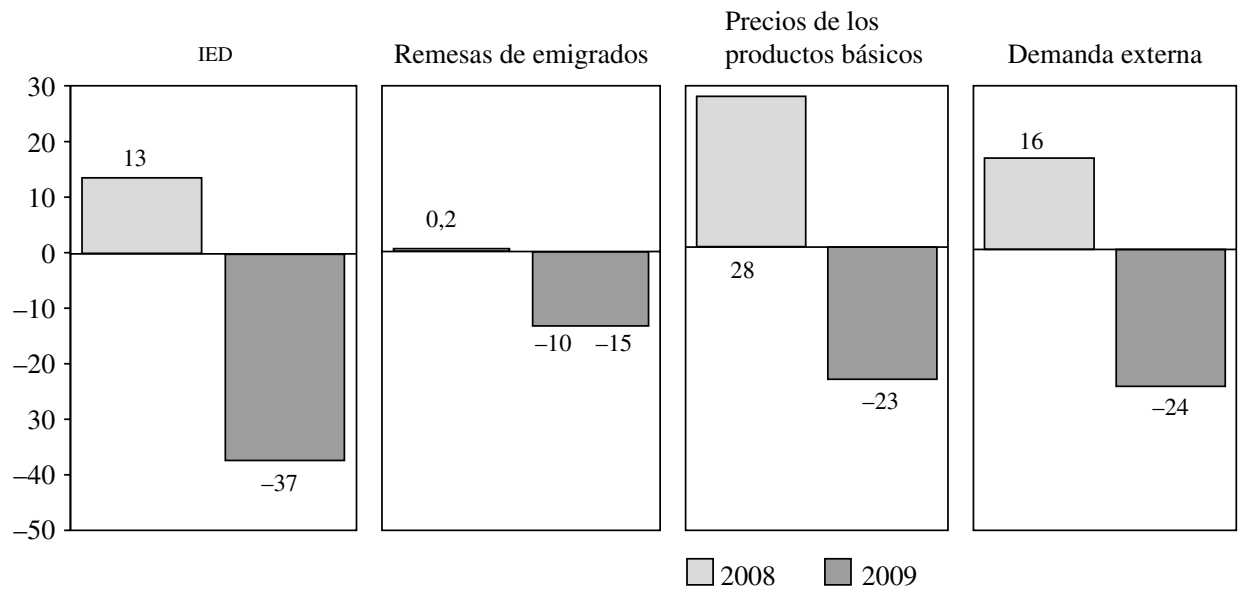

Flujos capitales financieros ${ }^{\mathrm{a}}$

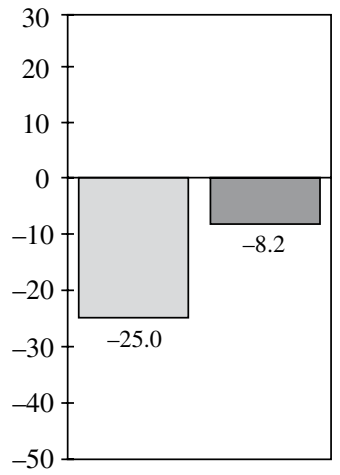

Fuente: Comisión Económica para América Latina y el Caribe (CEPAL), sobre la base de cifras oficiales.

Nota: Los valores para 2009 son proyecciones.

a Corresponde a la cuenta financiera, más errores y omisiones, deducida la inversión extranjera directa (IED). 
Si bien el énfasis de los efectos de la crisis se centra en el crecimiento económico, no hay que olvidar que dentro de las consecuencias más significativas de esta crisis están aquellas relacionadas con el empleodesempleo y la pobreza. Los efectos en el empleo han sido considerables (véanse los gráficos 7 y 8): la tasa de desempleo urbano, que había disminuido entre el primer y cuarto trimestre de 2007 de $8,9 \%$ a $7,2 \%$, ha repuntado como consecuencia de la crisis, situándose en alrededor de 8,3\% en 2009. Al aumento del desempleo hay que añadir que en algunos países de América Latina y el Caribe se observa un deterioro en la calidad del empleo. Por otra parte, las personas en situación de pobreza se incrementarían en 9 millones. Como se observa en el gráfico 8 , el costo social por causa de la crisis es mayor que los 9 millones de pobres adicionales proyectados, dado que si se hubiera mantenido el desempeño anterior la pobreza podría incluso haber disminuido en aproximadamente 5 millones de personas (CEPAL, 2009a; CEPAL, 2009f).

Conviene resaltar que la región reaccionó a la crisis desde una posición favorable en la macroeconomía, como se vio precedentemente, con superávit en la cuenta corriente y superávit fiscal (véase el gráfico 1), y a partir de una situación social que era por lejos la mejor de los últimos 40 años. La repuesta a la crisis cuyo origen era exógeno a las economías latinoamericanas se dio con la implementación de políticas contracíclicas en lo fiscal y monetario, que permitieron mitigar el impacto sobre el crecimiento, la actividad económica, el empleo y la pobreza (Kacef y Jiménez, 2009).

Ante la limitación para aplicar políticas monetarias debido a la baja monetarización de las economías de la región, la política fiscal se reveló importante para lograr un impulso en el nivel de actividad en el corto y mediano plazo, dadas las dificultades fiscales e institucionales en muchos de los países (la falta de proyectos, la constitución de unidades de gasto sectoriales y la complejidad institucional necesaria para disponer, erogar y evaluar los gastos). A pesar de estos obstáculos, en algunos países se incrementó la tasa de expansión del gasto público y se implementaron políticas sectoriales dirigidas a la construcción de viviendas (por su repercusión en el empleo y la demanda doméstica), de apoyo a las PYME (por su importancia en la generación de empleo), y de respaldo a sectores económicos, en especial el agrícola, y con mayor énfasis en los programas sociales, algunos de ellos focalizados en políticas de empleo (véase el gráfico 9) (CEPAL 2009e; Sojo, 2009).

En la segunda mitad del año 2009 comenzaron a generalizarse señales positivas en las economías de la región. La producción industrial y las exportaciones

GRÁFICO 7
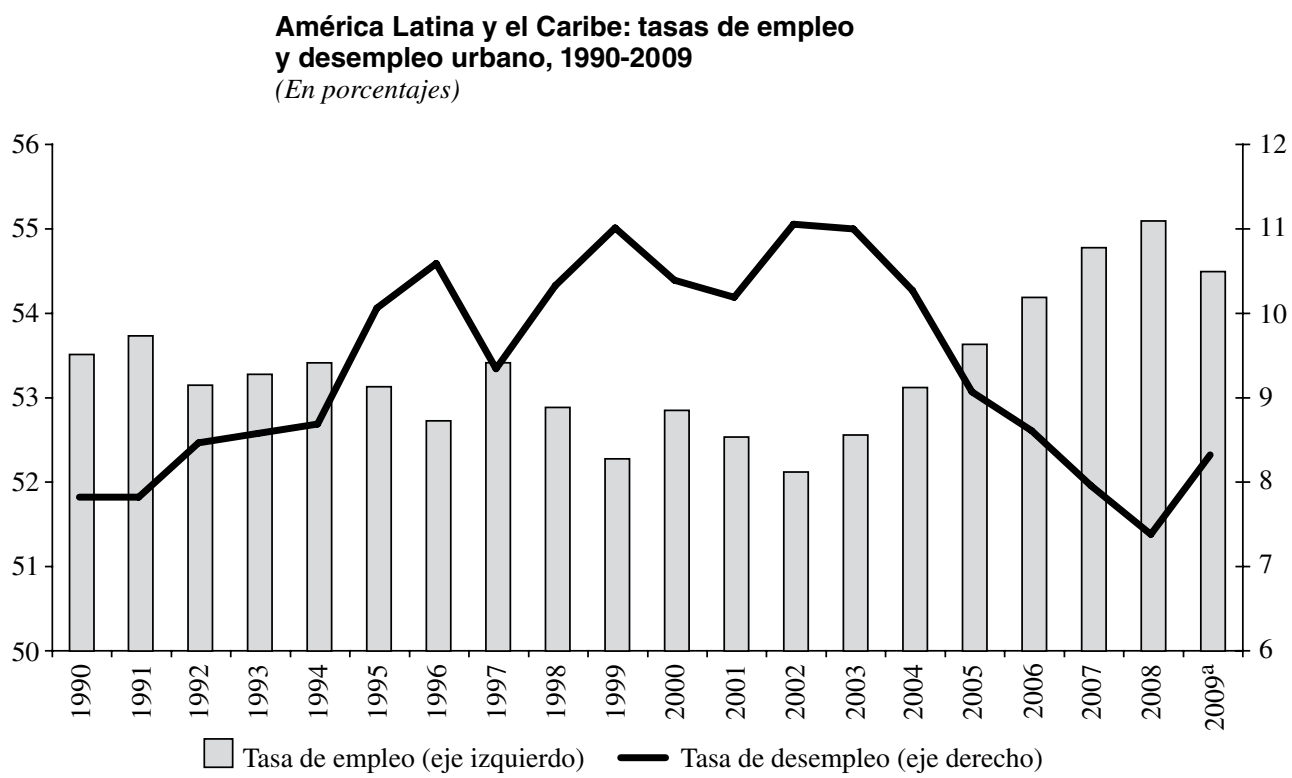

Fuente: Comisión Económica para América Latina y el Caribe (CEPAL), sobre la base de cifras oficiales.

a Estimación. 
GRÁFICO 8

\section{América Latina y el Caribe: evolución de la pobreza}

y repercusión estimada de la crisis

(En millones de personas)

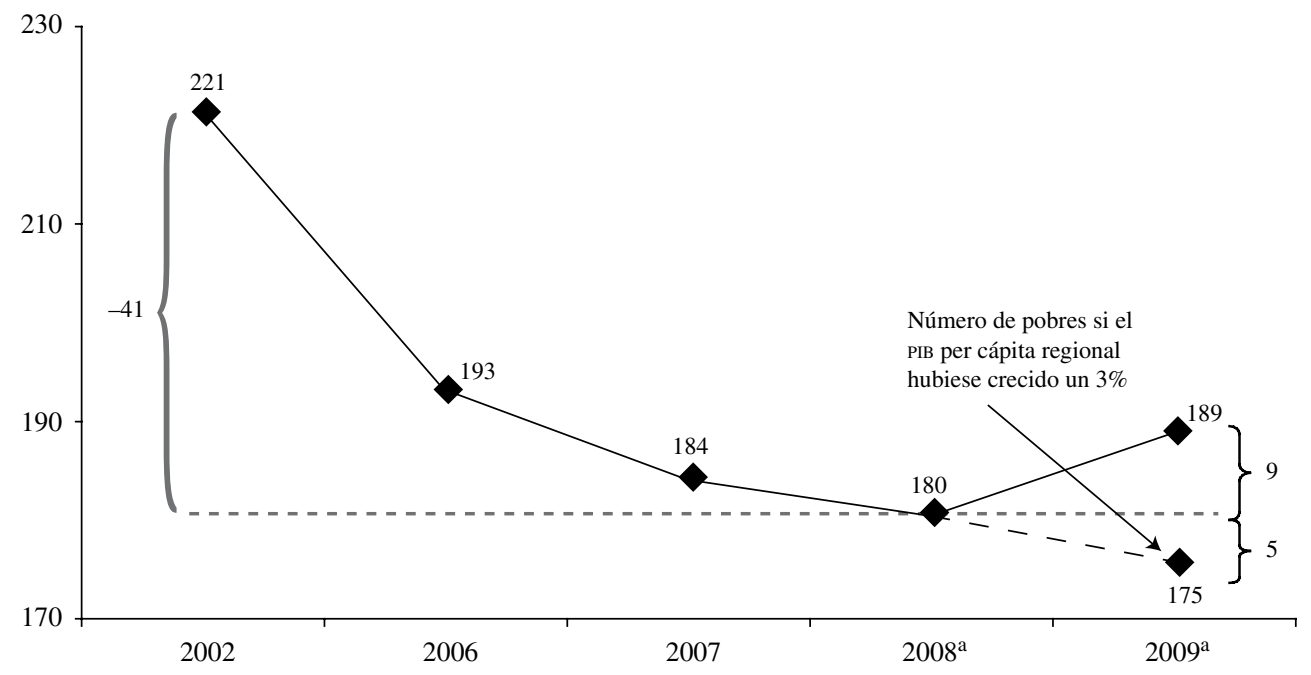

Fuente: Comisión Económica para América Latina y el Caribe (CEPAL), sobre la base de cifras oficiales.

a Estimación.

GRÁFICO 9

América Latina y el Caribe: composición de la cartera de programas sociales anunciados a partir de la crisis (En porcentajes)
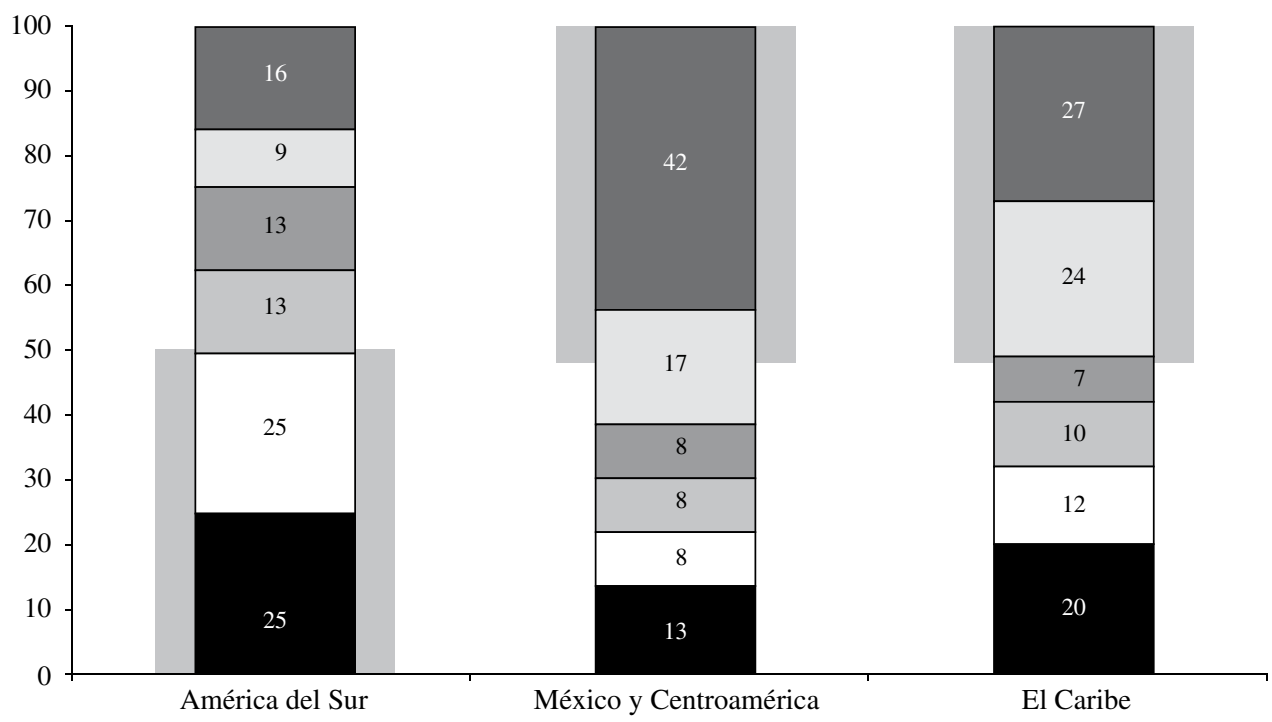

América del Sur

México y Centroamérica

El Caribe

Subsidios al consumo

Seguridad social

Atención del desempleo

Aumentos salariales $\square$ Generación de empleo $\square$ Familias pobres

Fuente: Comisión Económica para América Latina y el Caribe (CEPAL), sobre la base de información oficial. 
iniciaron su recuperación, al tiempo que el aumento del nivel de actividad global y de los volúmenes de comercio internacional impulsaron la demanda de productos básicos, permitiendo mayores precios y mejoras en los términos del intercambio. Los mercados de acciones volvieron a recuperar los valores previos a la crisis, mientras que la región volvió a acceder a la oferta internacional de crédito.

El crecimiento proyectado para el año 2010 es de $4,1 \%$ y se espera que sea algo superior en América del Sur que en el resto de la región, dado el mayor tamaño relativo de los mercados internos en algunos países y la más amplia diversificación de los mercados de exportación (CEPAL, 2009a). A esa expectativa también contribuye la mayor participación de China en el comercio de varios países y la recuperación de los precios de los productos básicos. Inversamente, se espera un crecimiento más lento en las economías más abiertas y con una cartera de socios comerciales menos diversificada y más concentrada en el comercio de manufacturas (como en México y Centroamérica). Algo similar puede decirse de las economías del Caribe que, en algunos casos, atraviesan por una compleja situación financiera y cambiaria. En general, entre los factores que sostienen este crecimiento se cuentan fundamentalmente la recuperación en el consumo privado y el alza de la formación bruta de capital fijo, liderada en parte por los paquetes de estímulo fiscal cuyos efectos se harán sentir de manera plena en 2010. Además, hay que resaltar que los precios de los commodities han repuntado (en particular energía y minerales) llegando a niveles de 2006 .

\section{$\mathrm{V}$}

\section{El escenario postcrisis y}

\section{las restricciones estructurales}

Existe, no obstante, una creciente percepción de que los efectos que esta crisis económica ha legado moverán la dinámica de crecimiento y la articulación de las relaciones económicas, financieras y comerciales hacia lo que recientemente se ha dado en llamar una "nueva normalidad" en la economía mundial, que estaría configurada por los siguientes elementos: menores tasas de crecimiento económico mundial, mayor significación para las economías emergentes, desaceleración de los flujos comerciales, tendencia a un mayor proteccionismo comercial, reducción del crédito externo (por lo menos hasta que sea diseñada una nueva arquitectura financiera global que ofrezca condiciones más estables de acceso al capital externo) y tránsito hacia economías con menores emisiones de $\mathrm{CO}_{2}$, con marcadas repercusiones en las condiciones de ingreso a los mercados externos y la creación de capacidades productivas y tecnológicas.

La reciente crisis económica redefinió las condiciones en que América Latina y el Caribe enfrentaba los desafíos del crecimiento y la equidad. Si bien los contornos de la salida de la crisis no están bien definidos, es probable que el mundo postcrisis se caracterice por un menor crecimiento global, debido a una contracción en la demanda agregada de los países desarrollados. De hecho, se espera que la tasa de crecimiento del PIB potencial de los países de la Organización de Cooperación y Desarrollo Económicos (OCDE) baje en el mediano plazo cerca de 1 punto porcentual por efecto de la crisis (OCDE, 2009). En este contexto, las economías emergentes podrían jugar un papel protagónico más destacado. La caída de la demanda de importaciones por parte de las economías desarrolladas estrechará el espacio para que las economías emergentes puedan colocar sus productos en estos mercados, exacerbando la competencia e incentivando, al mismo tiempo, la adopción de estrategias de crecimiento orientadas sobre todo a los mercados internos, al menos en aquellas economías de mayor tamaño relativo.

Dinamizar el crecimiento requiere cambios en la composición de la demanda agregada mundial que no serán fáciles de alcanzar. En el mediano plazo, para recuperar el ritmo de crecimiento global previo a la crisis es preciso restablecer el equilibrio de la demanda agregada entre países desarrollados y emergentes. Pero hay falta de consenso y claridad en cómo llevarlo a cabo. A título de ejemplo, los países desarrollados tienen gran peso en el consumo mundial (Estados Unidos: $34 \%$ y la OCDE: $84 \%$ del consumo mundial en promedio para el período 2004-2007). Por otra parte, si bien las economías emergentes (Asia, China) disponen de espacio para 
aumentar su demanda interna, enfrentan limitaciones en su capacidad para realizarlo.

Además, se requiere recuperar el equilibrio entre la demanda agregada interna pública y privada. Resulta complejo mantener los estímulos fiscales indefinidamente, ya que ello implica un crecimiento significativo de la deuda pública. Esto evidencia la necesidad de compensar parte de la demanda pública mediante demanda privada.

Asimismo, esta "nueva normalidad" no solo presentará un menor crecimiento económico, sino también considerables limitantes a la expansión del sector financiero. Esto entrañará menores flujos financieros mundiales y hacia regiones en desarrollo. De manera consistente con la restricción crediticia, los flujos financieros transfronterizos, que habían pasado de 1 billón de dólares a 10 billones de dólares entre 1990 y 2007 (representando el 5\% y el 21\% del PIB mundial, respectivamente), decayeron de manera significativa en 2008 a 3,1 billones de dólares (2\% del PIB mundial) (McKinsey, 2009). Los flujos financieros privados a las economías en desarrollo se redujeron prácticamente a la mitad entre 2007 y 2008 , pasando de 1.250 millones de dólares a 650 millones de dólares. En 2009 llegarían a los 350 millones de dólares y a un estimado de 670 millones de dólares en 2010 (IFI, 2009).

A esta tendencia contribuirán el aumento del sesgo doméstico, un mayor proteccionismo financiero y los cambios en la regulación financiera existente. En tal sentido, se espera una menor integración financiera a nivel global, con menos flujos transfronterizos (proteccionismo financiero). Los cambios en la regulación financiera redundarán en una supervisión y regulación mucho más exhaustivas para eliminar los vacíos existentes antes de la crisis, las que serán más amplias y abarcarán a los diferentes instrumentos, así como a los distintos participantes del mercado. Esta dinámica derivará en un cambio de modelo con miras a una banca más transparente, con menores niveles de riesgo y de apalancamiento.

Por último, la nueva normalidad también introducirá cambios en los patrones comerciales. En particular, se prevé una desaceleración del comercio mundial. Las previsiones apuntan a que el volumen de comercio mundial se retraería del orden de un $10 \%$ en 2009 , para luego crecer en 2010 a una tasa en torno del 1\% (OMC, 2009; FMI, 2009). La caída se produciría en mayor medida en las naciones desarrolladas, seguida de una contracción del comercio en China.

Estas proyecciones responden a la esperada desaceleración prolongada de la demanda de importaciones de las economías desarrolladas, a un mayor uso de prácticas "proteccionistas", a una lenta recuperación de los sistemas de crédito y pagos y a la disrupción de las cadenas de producción global.

\section{Inversión y brecha de productividad}

Aun reconociendo que las políticas macroeconómicas actúan en el corto plazo, es importante reconocer que la estructura productiva, o algunos rasgos fundamentales de ella — como son, por ejemplo, las inversiones y la dinámica de la productividad_-, condicionan y afectan a la dinámica de las variables macroeconómicas (Ocampo, 2005). Los flujos financieros especulativos y el riesgo de crisis locales que se generaron en los momentos de interrupción de los flujos de capitales afectaron a la propensión a invertir, influenciando así la dinámica de la productividad de la región. De hecho, en el largo plazo, la volatilidad en el crecimiento del producto y la inestabilidad de las entradas netas de capitales se tradujeron en períodos de subutilización de la capacidad productiva y en un deterioro del capital acumulado. La volatilidad de estos flujos —que ha contribuido a la volatilidad del crecimiento económico- y el estancamiento del ahorro interno representan un serio límite a la reanudación de las inversiones y a una expansión de la capacidad productiva.

Una vez más, al estar saliendo de una recesión, las economías de América Latina y el Caribe muestran un PIB efectivo inferior al potencial, lo que da margen para que la recuperación sea rápida. Pero si no vuelve a crecer la inversión y con ella la capacidad productiva, se truncaría la expansión de la frontera de producción y la consecuente elevación del PIB potencial. En este contexto, la brecha en los niveles de inversión con respecto al PIB sigue condicionando el patrón de desarrollo de la región (véase el gráfico 10 ).

Existe un importante debate acerca de cuáles son los factores explicativos del crecimiento económico y la frontera de producción en el largo plazo. Si bien este debate no se ha agotado, las opiniones convergen hacia la idea de que la capacidad de innovar y de difundir rápidamente las mejores prácticas tecnológicas internacionales en el seno de la estructura productiva es una de las claves de dicho crecimiento. Esta perspectiva ha sido defendida desde sus orígenes por la CEPAL (Prebisch, 1949) y representa un aspecto muy relevante de sus contribuciones más recientes (CEPAL, 2007). En la perspectiva cepalina, el aprendizaje tecnológico se relaciona estrechamente con la estructura productiva y con el marco institucional vinculado a las actividades de educación, ciencia y tecnología. 


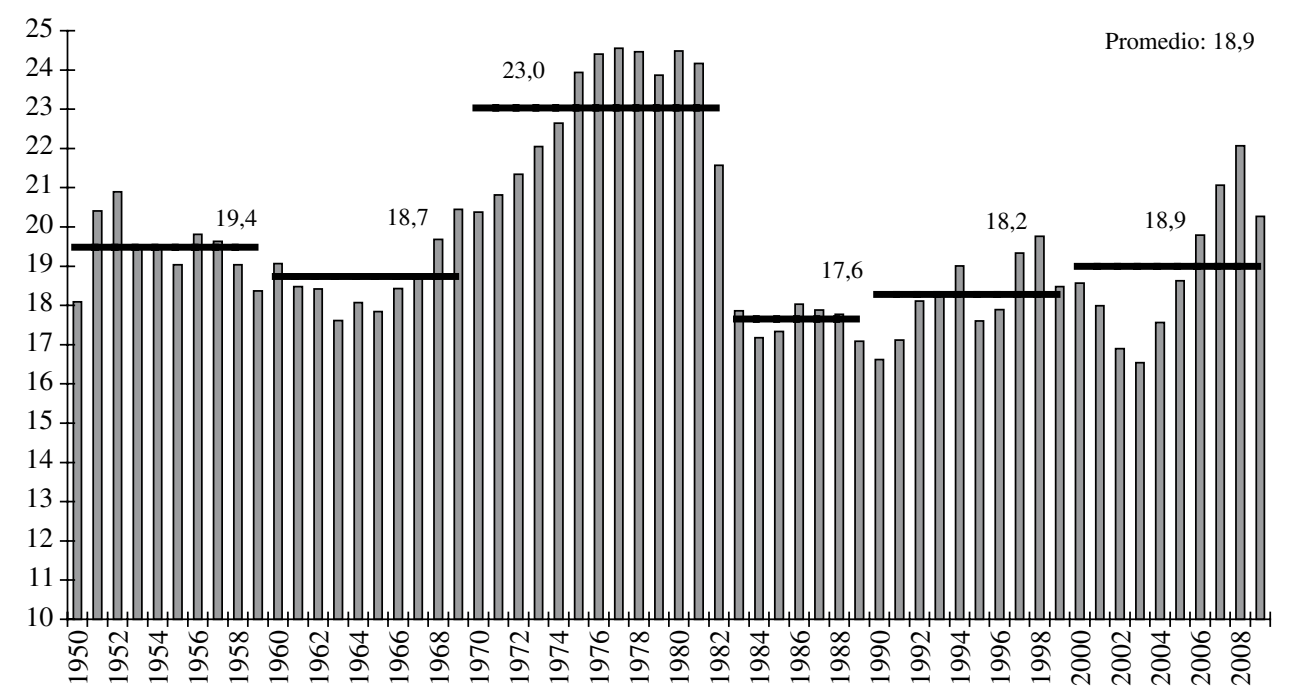

Fuente: Comisión Económica para América Latina y el Caribe (CEPAL), sobre la base de cifras oficiales.

Se entiende que cuanto mayor es la gravitación en la estructura productiva de los sectores intensivos en tecnología, más rápidamente se generan procesos de aprendizaje, se eleva la tasa de innovación y se expanden las demandas interna e internacional por los bienes producidos en el país. Este último efecto se explica no solo porque los bienes más intensivos en tecnología tienen una demanda más dinámica, sino también porque las capacidades tecnológicas son fundamentales para permitir que la economía se adapte y responda a las frecuentes transformaciones que ocurren en el mercado internacional. Sin esas capacidades, las exportaciones perderían dinamismo y se reduciría el crecimiento, generando (como ha sido común en la región) ciclos de expansión y contracción (stop and go) pautados por crisis externas e intensamente afectados por períodos de precios favorables en los commodities o de disponibilidad de financiamiento externo.

En la literatura empírica se reconoce ese papel clave de la estructura productiva y la incorporación y difusión del cambio técnico en el crecimiento económico (CEPAL, 2007). En el período posterior a la crisis, la recuperación está relativamente asegurada ya que se parte de niveles muy bajos de producto, pero un crecimiento perdurable a tasas altas (que implica un aumento de la inversión y del PIB potencial) es más dudoso. A pesar del último período de bonanza, la evolución de la economía y del sector industrial en los últimos años no parece haber conducido a cambios estructurales relevantes; los aspectos mencionados, relacionados con el balance comercial industrial, son en buena medida un reflejo de esa situación. Una conclusión similar surge de comparar directamente los niveles de productividad alcanzados por los países de la región con los de los Estados Unidos. La enorme diferencia existente es una medida de la dimensión de los desafíos que la región tendrá que enfrentar en los próximos años.

En efecto, la evolución del índice de productividad laboral relativa de América Latina y el Caribe en el sector industrial permite ver que no se verifica un cierre de la brecha de productividad a lo largo de todo el período considerado (véase el gráfico 11). A partir de los años ochenta se observa una tendencia a la ampliación de la brecha, que se reduce en los años noventa. Sin embargo, a partir de mediados de la década de 1990 el índice de productividad relativa vuelve a caer (y, por lo tanto, la brecha de productividad se amplía). Es importante constatar que la contracción es particularmente aguda en los últimos seis años de la serie. Esto se debe a dos hechos; en primer lugar, la productividad laboral del sector industrial de los países de la región se incrementó en un 2\% anual entre 2003 y 2007. Y esto representa el peor desempeño de este indicador en los últimos 36 años, con la excepción de 


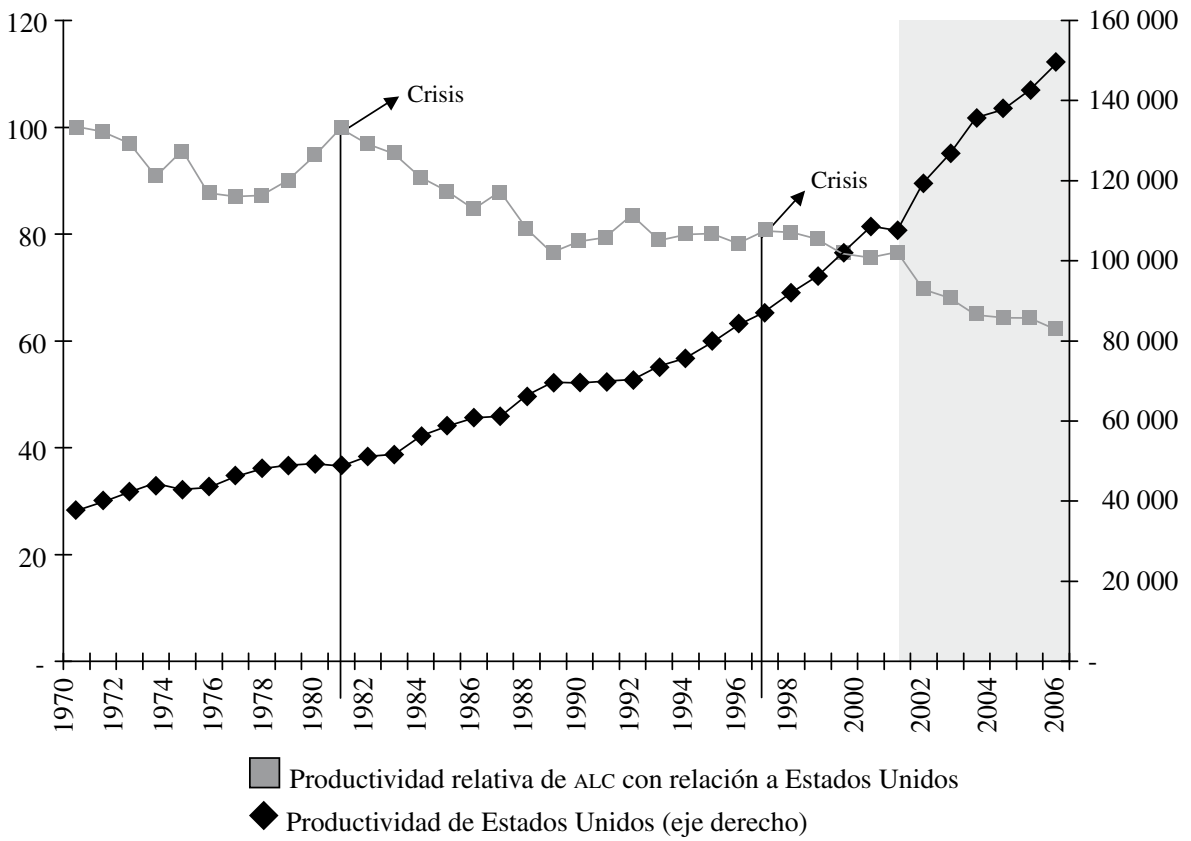

Fuente: Comisión Económica para América Latina y el Caribe (CEPAL), sobre la base de cifras oficiales.

Nota: Productividad medida en los sectores industriales.

ALC: América Latina y el Caribe.

la "década perdida" de los años ochenta. En segundo lugar, la productividad de los Estados Unidos, después de haber crecido durante 20 años a un ritmo del 3\% anual aproximadamente, a partir de mediados de los años noventa se incrementa, pasando a un valor de alrededor del $5 \%$ anual.

Es importante enfatizar el papel de la interacción entre el corto y el largo plazo y de distintas políticas económicas con respecto a la evolución de la productividad. Cada vez que se verifica una perturbación (shock) (en los precios o en la tasa de cambio real) se registra una caída de la productividad a lo largo del proceso de ajuste (Cimoli y Porcile, 2008).

En otras palabras, la perturbación produce un impacto estructural con los consiguientes cambios y readaptaciones en los procesos productivos, que son costosos y requieren tiempo para recuperar la competitividad previa. La velocidad con que las firmas responden a las perturbaciones y la dirección del cambio son cruciales para que sigan siendo competitivas en el mercado internacional. Por consiguiente, habrá un intervalo durante el cual la economía experimentará necesariamente una caída en el crecimiento de la productividad, que para el caso de América Latina y el Caribe no implica una ayuda en su mejora de largo plazo.

Claramente, el tiempo necesario para la readaptación depende de muchos factores, tales como las especificidades de los activos de las firmas, los diferenciales de productividad entre sectores y empresas, la estrategia de gestión de la empresa y las características generales del capital humano. Es decir, hay un cierto grado de rigidez en las capacidades tecnológicas y productivas de las firmas que determina el tiempo y la dirección del proceso de readaptación. Esto puede generar una nueva empresa más competitiva, con una combinación de productos cada vez más diversificada, o también puede redundar en la desaparición de la firma.

La consecuencia es que, en términos de productividad del trabajo, América Latina y el Caribe no cierra la brecha con la frontera (representada por los Estados Unidos). Los efectos de las distintas crisis son claramente visibles en el gráfico 11, donde se puede observar una descomunal caída de la productividad relativa durante la crisis de la deuda en los años ochenta, una moderada 
recuperación a partir de comienzos del decenio de 1990 y una nueva contracción a partir de la segunda mitad de la década (crisis del "tequila"). Cabe destacar que detrás de esas fluctuaciones hay períodos alternos de apreciación cambiaria, liberalización comercial y deuda externa creciente, seguidos por nuevas devaluaciones tal como se mencionó anteriormente.

El tema de la brecha de productividad es sin duda clave para sostener la competitividad internacional con equidad, como ya lo señalara Fajnzylber (Fajnzylber, 1990). Pero hay una nueva variable clave en la transformación productiva cuya importancia ha crecido sostenidamente a lo largo del tiempo, a saber, la de la sostenibilidad ambiental, como se discute a continuación.

\section{Sostenibilidad del cambio estructural y medio ambiente}

Para llegar a un patrón de desarrollo virtuoso y sostenible en el tiempo, además de mantener los equilibrios macroeconómicos, se requerirá por supuesto de un proceso de cambio estructural que permita reducir las diferencias de productividad con respecto a los países más desarrollados (convergencia productiva), como la CEPAL lo ha manifestado desde la época de transformación productiva con equidad. Hoy son muy claras las señales de que el patrón de crecimiento predominante en el mundo no es compatible con la preservación ambiental. Los costos estimados del deterioro ambiental - entre los que resaltan los problemas climáticos, con sus secuelas destructivas del capital humano, físico y natural- se hacen cada día más evidentes. Sin embargo, desde una perspectiva de sostenibilidad ambiental, actualmente existe el imperativo de lograr ese sendero de crecimiento con el menor consumo de energía por unidad de producto y con menores impactos sobre el medio ambiente.

El escenario que surge de cerrar la brecha productiva sin agudizar los problemas ambientales puede definirse como de convergencia sostenible. De hecho, se observa que los sectores intensivos en ingeniería usan menos energía por unidad de producto que los intensivos en recursos naturales o mano de obra. Mientras tanto, el cambio de estructura en la región no se ha dado en la dirección correcta (ni en lo tecnológico, ni en lo energético): en el escenario predominante se combina divergencia en productividad con un patrón de consumo energético insostenible en el tiempo (divergencia no sostenible). Este tipo de patrón de crecimiento se relaciona frecuentemente con el uso intensivo de recursos naturales, ya que prevalece en sectores maduros con una incorporación del cambio técnico más lenta. Además, el mayor uso de recursos naturales involucra un consumo energético más elevado. Sobre la base de los datos presentados anteriormente, se puede concluir que se expande el consumo de energía por unidad de producto con respecto a la frontera energética y, simultáneamente, que la región no logra reducir su retraso productivo. Una descripción gráfica de esta situación se presenta en el gráfico 12 en que se muestra una "tijera" que se abre con el transcurso del tiempo, describiendo la expansión de las brechas productiva y energética de América Latina y el Caribe con respecto a los Estados Unidos.

Particularmente en el Caribe, se presentan algunos de los más altos crecimientos en las emisiones provenientes de las energías fósiles, como ha sucedido en Trinidad y Tabago, Jamaica y la República Dominicana, aunque algunos países caribeños han hecho considerables avances en materia de reforestación, como sucede en Cuba y la República Dominicana. En el contexto latinoamericano, se espera que esta sea una de las regiones más afectadas por la combinación de efectos del cambio climático expresados en blanqueamiento del $75 \%$ de los bancos coralinos en los próximos 30 a 50 años (Samaniego, 2009), debido al incremento de la temperatura oceánica, la pérdida o erosión del territorio causadas por la expansión térmica del mar y el aumento de intensidad de los fenómenos extremos hidrometeorológicos como inundaciones y huracanes. Dada su limitada diversificación económica, altamente dependiente del sector primario y del turismo, las repercusiones para la región podrían ser muy significativas económicamente.

La eficiencia energética y la protección ambiental son algunos de los desafíos para América Latina y el Caribe en el nuevo contexto internacional y se insertan en las exigencias impuestas por el cambio climático. La CEPAL proyectó que sin acciones internacionales de mitigación, la región podría sufrir para fines del siglo pérdidas cuantiosas en el sector agrícola y en la biodiversidad, fuertes presiones sobre la infraestructura e incremento en la intensidad de eventos extremos, que se acumularían hasta representar cifras importantes del PIB actual (CEPAL, 2009c). Si no se actúa con urgencia para modificar esta trayectoria, en las próximas décadas las tensiones ambientales alcanzarán niveles sin precedentes en la historia. La evidencia científica es muy concluyente al respecto y se exigen cambios urgentes en los modos de producción y consumo, especialmente de la energía. 


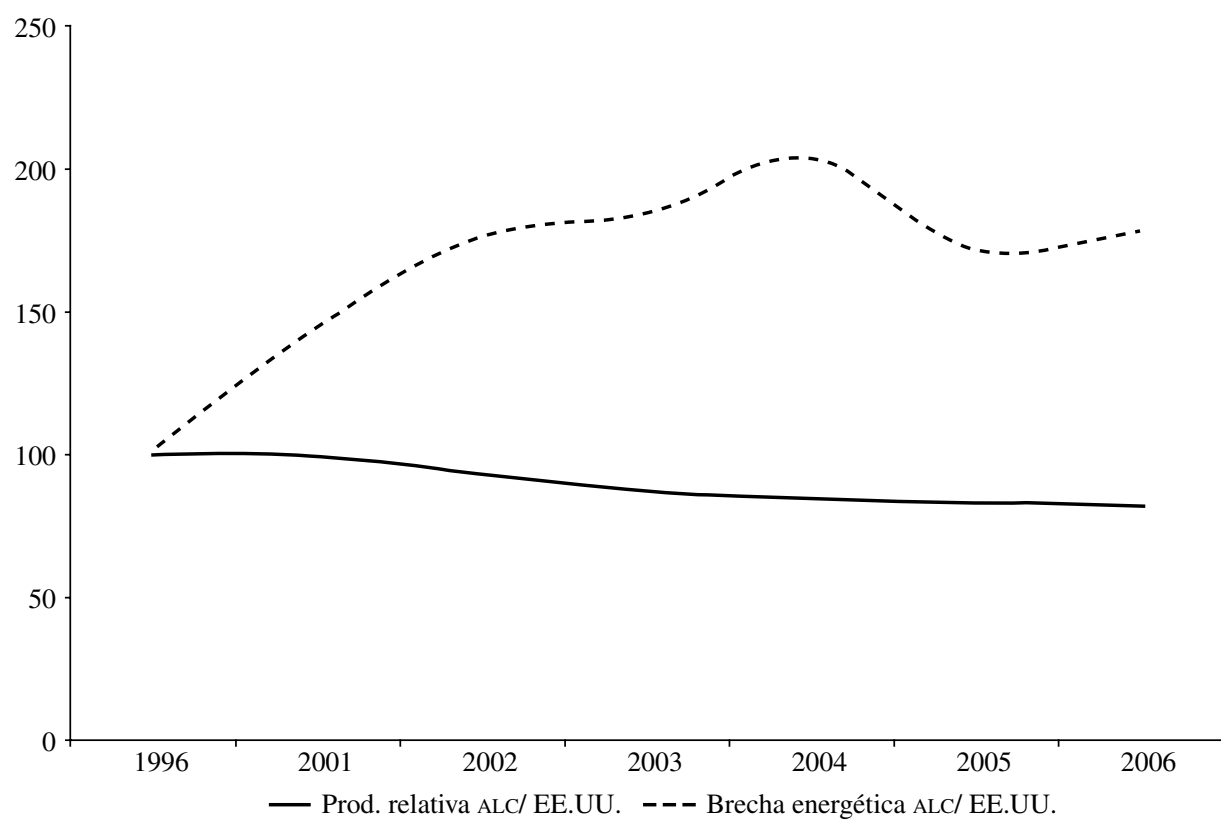

Fuente: Comisión Económica para América Latina y el Caribe (CEPAL), sobre la base de cifras del Programa de Análisis de la Dinámica Industrial (PADI) y las encuestas industriales de los países (Instituto Nacional de Estadísticas (INE) de Chile; Departamento Administrativo Nacional de Estadística de Colombia (DANE); Instituto Nacional de Estadística, Geografía e Informática (INEGI) de México; Instituto Brasileño de Geografia y Estadística (IBGE) y la Oficina de Análisis Económicos (BEA, por su sigla en inglés) de los Estados Unidos.

a Los países considerados son Brasil, Chile, Colombia y México.

b La brecha energética se mide por el cociente entre el indicador de intensidad energética de los países de la región y el correspondiente a los Estados Unidos.

Tras los escasos resultados obtenidos en la Cumbre Mundial sobre el Cambio Climático realizada en Copenhague en diciembre de 2009 (limitar la subida de la temperatura del planeta a dos grados, sin establecer cifras de emisiones para 2020 y 2050 , pero comprometiendo recursos para los países pobres a fin de que detengan la deforestación), que por cierto carecen de obligatoriedad jurídica, el desafío de transitar a economías con un menor contenido de carbono renueva su urgencia. Se mantienen abiertas dos modalidades internacionales; la primera apunta a un camino negociado, sobre la base de valores compartidos, tiempos acordados, criterios y esfuerzos simultáneos con responsabilidades comunes, pero diferenciadas, en el marco de las negociaciones multilaterales. La segunda abre una ruta de iniciativas unilaterales que se aplican de manera indiscriminada, sin distinguir niveles de desarrollo relativo, y que solo obedecen a las leyes de la competencia.
Entre las medidas que formarán parte de la "nueva normalidad" climático-económica se contará la aplicación de regulaciones unilaterales al comercio, basadas en el contenido de carbono de las mercancías exportadas a las economías desarrolladas, lo que implica un serio riesgo de que la mitigación termine siendo (por esa u otras vías económicas, como el acceso condicionado al crédito) desplazada en su mayor parte hacia las economías en desarrollo. También se está explorando la aplicación -a partir del año 2020 — de aranceles compensatorios sobre bienes importados intensivos en carbono. Los países en desarrollo deberán prepararse para evitar una eventual pérdida de mercados de exportación ante la aparición de competidores mejor adaptados para enfrentar estas exigencias.

En suma, los problemas de sostenibilidad y la nueva normativa que emerge en el mundo podrían convertirse en otra restricción al crecimiento económico de América Latina y el Caribe. Pero si ese nuevo contexto se aborda 
como una oportunidad para renovar las infraestructuras, mejorar los procesos productivos y tecnológicos orientados a la creación de modos de transporte más eficientes, y lograr formas de produción con menor emisión de gases, entonces puede abrirse un nuevo horizonte de crecimiento de largo plazo. Para ello se requiere articular los estímulos a la inversión (aún muy bajos) y los sistemas nacionales de innovación (aún débiles) para impulsar las tasas de inversión e innovación a partir de las tecnologías menos contaminantes. Se hace necesario, entonces, garantizar el acceso y acelerar la aproximación de América Latina y el Caribe a la frontera tecnológica en tecnologías sostenibles.

\section{Distribución y brecha de equidad}

América Latina y el Caribe sigue mostrando elevados niveles de desigualdad y, como ya fue mencionado, no es posible pensar en su reducción y en la de la pobreza en un contexto de bajo crecimiento, en que las tasas de empleo y de productividad permanezcan bajas. El crecimiento no garantiza de por sí la distribución, pero junto con políticas sociales más decididas y coherentes bajo un enfoque de derechos (Hopenhayn, 2001) es un componente crítico para mejorarla. Por otra parte, los propios aumentos de productividad hacen viable (bajo ciertas condiciones) que producto, salarios y empleo se expandan en paralelo, contribuyendo al redimensionamiento de la heterogeneidad presente en el sistema productivo y de la brecha de productividad (Infante y Sunkel, 2009).

Los indicadores sociales reflejan una tendencia positiva que es fruto del crecimiento, pero también de avances en la institucionalidad y de las políticas públicas en el combate a la pobreza, la exclusión y la desigualdad. La primera evidencia de esta propensión es el sostenido crecimiento del gasto social por más de dos décadas, tanto en términos per cápita como en términos del porcentaje del PIB. Los cambios distributivos ocurridos en el período contribuyeron parcialmente a la reducción de la pobreza, aunque no en todo su potencial. La variación de las tasas de pobreza e indigencia puede ser desagregada en dos componentes, el crecimiento del ingreso medio de las personas, o "efecto crecimiento", y los cambios en la forma en que se distribuye este ingreso, o "efecto distribución". Este tipo de análisis permite ver que el "efecto crecimiento" fue el principal factor explicativo en el retroceso de la pobreza entre 1990 y 2008 , representando alrededor de un $85 \%$ de esta, mientras que el "efecto desigualdad" dio cuenta del $15 \%$ restante. En tanto que la contribución de las mejoras distributivas a la disminución de la pobreza se dio especialmente en el período 2002-2008 (CEPAL, 2009d).

Los ingresos provenientes del trabajo son la fuente que aportó en mayor medida a la reducción de la pobreza entre 1990 y 2008. La variación positiva del ingreso laboral por persona se debió principalmente a la aminoración de la tasa de dependencia demográfica (denominada habitualmente como el "bono demográfico") en todos los países - excepto en Uruguay—, y a un aumento importante de la tasa de actividad económica. Igualmente, el ingreso laboral por ocupado presentó diferencias notables entre los países. Los países con mayores retrocesos de la pobreza (en términos de la variación porcentual de la tasa) —Brasil, Chile, Costa Rica, Ecuador (área urbana) y Panamá (área urbana)— son precisamente los que presentaron los incrementos más marcados en el ingreso por ocupado en los hogares pobres. Colombia constituye una excepción a este respecto, ya que si bien tuvo un aumento importante en esta variable, presentó un ritmo bastante menor en la merma de la pobreza, en parte debido al engrosamiento del desempleo. En los demás países, el ingreso laboral por ocupado tendió a decrecer.

Un aspecto preocupante de la evolución de la pobreza en América Latina y el Caribe es la persistencia de las brechas en la vulnerabilidad a la pobreza según las características demográficas de las personas, particularmente la edad, el sexo y la etnia. Uno de los rasgos más determinantes de la pobreza es la condición de ser niño. La incidencia de la pobreza entre los niños menores de 15 años excede en promedio 1,7 veces la registrada entre las personas mayores de esa edad. Entre 1990 y 2008, el cociente entre las tasas de pobreza de los niños y los adultos aumentó en la mayoría de los países de la región, presentándose los mayores incrementos en Brasil, Panamá y Uruguay.

A pesar de las políticas activas implementadas, la crisis revirtió dos tendencias que se estaban consolidando en los últimos cinco años: la contracción del desempleo y la pobreza. En este contexto, el gasto público social - junto con el gasto para las políticas productivas- es determinante para consolidar los logros alcanzados y profundizar la equidad.

La crisis experimentada en América Latina y el Caribe a principios de los años ochenta impuso fuertes restricciones financieras al gasto público. Para cerrar la mayor brecha fiscal (en la próxima sección se vuelve sobre este tema), las opciones de política eran aumentar la recaudación físcal o reducir el gasto público, y fue esta última opción la variable de ajuste para sanear las cuentas fiscales, con el consecuente efecto negativo en 
el gasto social en un contexto de deterioro de los niveles de bienestar.

La tendencia creciente del gasto público social desde comienzos de los años noventa indica el compromiso progresivo de los países latinoamericanos de asignar recursos públicos a las políticas sociales, dándoles mayores garantías de financiamiento, y más estabilidad y legitimidad institucional, esfuerzos que en gran medida han estado restringidos al grado de desarrollo alcanzado por los países (CEPAL, 2006). Ante los antiguos y nuevos riesgos sociales y económicos en cada país, la disponibilidad de los recursos públicos para financiar sistemas de protección está en directa relación con la capacidad de recaudación de los gobiernos. Pero en la región persisten las bajas cargas tributarias, que se vuelven factores muy limitantes en la confección de sus presupuestos. No obstante, los gobiernos han hecho considerables esfuerzos por aumentar sus presupuestos públicos —en un marco de mayor disciplina fiscal que antaño-, y en particular los destinados a funciones sociales. El gasto social en la región — pese a las iniciativas de los gobiernos en tal sentido- continúa siendo insuficiente en montos y no alcanza a tener la repercusión necesaria para mejorar el bienestar y la equidad. Su comportamiento sigue siendo procíclico y evidencia contracciones en períodos de crisis. Ello resalta la restricción y limitaciones presupuestarias de los países que registran los menores niveles de desarrollo, ya que son los que tienen menos capacidad para tomar medidas contracíclicas en períodos de contracción económica.

\section{Brecha fiscal y financiamiento de las políticas públicas}

El tema de la brecha fiscal deberá jugar un papel muy importante en el futuro diseño de políticas, ya que afecta a variables muy relevantes tanto en el corto plazo (como la inflación y el nivel de actividad) como en el largo plazo (pues afecta a la capacidad de financiar políticas sociales y productivas). Es necesario encontrar mecanismos de financiamiento de las políticas públicas que no entren en contradicción con los objetivos de la estabilidad macro, aprendizaje e innovación, e igualdad.

En el período comprendido entre 2002 y 2008 el manejo adecuado de la política fiscal (Martner, 2007), así como la coyuntura internacional y el entorno macroeconómico favorables, derivaron en mejoras en el diseño y manejo de la política macroeconómica y en la reducción de la vulnerabilidad de las cuentas públicas y externas, posibilitando la disminución del endeudamiento y la acumulación de reservas. Es conveniente resaltar que en 2006 y 2007 hubo superávit global a nivel regional por primera vez en la historia de América Latina y el Caribe (véase el gráfico 1).

Con el avance de la crisis al final de 2008, a los requerimientos preexistentes de atenuar la volatilidad, fortalecer el crecimiento y mejorar la equidad de las sociedades latinoamericanas y caribeñas se sumaron las nuevas demandas de políticas contracíclicas y de instrumentos de protección a la población más vulnerable ante impactos distributivos negativos. En este contexto de mayores demandas de gasto $\mathrm{y}$, al mismo tiempo, de menores ingresos fiscales a causa de la caída en los precios de los productos básicos y en el nivel de actividad, los mayores espacios de política alcanzados en los años anteriores se redujeron significativamente (los déficits fiscales en 2008 y 2009 fueron de $-0,3 \%$ y $-2,8 \%$ del PIB, respectivamente).

Sin embargo, la brecha fiscal no se restringe a condiciones coyunturales, y es en realidad un problema estructural de los países de la región que también se conecta con la característica desigualdad que prevalece en ellos.

Los múltiples problemas vinculados a una sociedad fragmentada, donde un pequeño porcentaje de la población concentra gran parte de la riqueza y amplios grupos de hogares se hallan por debajo de los niveles de subsistencia, plantean la redefinición del papel del Estado en la redistribución del ingreso. Las tres principales características que limitan el desempeño redistribuidor del Estado en la región son la baja presión tributaria, la regresividad de los sistemas de tributación y la deficiente orientación del gasto público.

Los países de América Latina y el Caribe tienen niveles de recaudación bajos (aunque hay variaciones importantes entre países). En promedio, la presión tributaria de la región es de alrededor del 18\% del PIB, un nivel pequeño en relación con el grado de desarrollo de América Latina y el Caribe, sobre todo si se lo compara con las necesidades de financiamiento implícitas en las demandas de políticas públicas. Esto significa que los sectores públicos tienen a su disposición una fuente muy limitada de recursos para responder a las demandas de bienes y servicios de amplios sectores de la población. Ello es aún más notorio en algunos países centroamericanos, que tienen niveles de presión tributaria cercanos al $10 \%$ del PIB y elevadas necesidades sociales, derivadas de niveles de pobreza sumamente altos.

Además, esta recaudación se efectúa por medio de sistemas tributarios regresivos, es decir, que acentúan las disparidades de ingreso. Menos de un tercio de la recaudación corresponde a impuestos directos, mientras que el grueso de la carga recae en impuestos sobre el 
consumo y otros tributos indirectos con claros efectos regresivos. Todo ello genera una distribución del ingreso después de los impuestos más inequitativa incluso que la distribución primaria. Se requiere entonces fortalecer la tributación directa y generar un mejor balance entre esta y la tributación indirecta. Cualquier intento por dotar al sistema tributario de un efecto redistributivo en favor de los más pobres requerirá rediseñar el impuesto a la renta y los impuestos patrimoniales. Estos últimos deberían alcanzar una mayor participación en la recaudación total, al mismo tiempo que un grado de progresividad más alto. Pero estos esfuerzos deben ir acompañados de un mayor control de la evasión y la elusión tributarias, fenómenos que constituyen importantes fuentes de inequidad, derivan en injusticias que perjudican la legitimidad de los sistemas tributarios, y terminan por afectar a su capacidad recaudatoria. Así, a la demanda de mayor recaudación se agrega la de corregir, tanto como sea posible, el sesgo regresivo de la estructura tributaria.

Por parte del gasto, es necesario evaluar la relevancia de su volumen y calidad. En períodos de crisis como la actual, el incremento o mantenimiento del gasto social se vuelve prioritario, y es necesario estimar su potencial redistributivo y la capacidad de focalización en los grupos de población más vulnerables.

En resumen, hay problemas de cantidad y calidad del gasto público que deben ser enfrentados, junto con la necesidad de redefinir la relación entre contribuyentes y beneficiarios, que ha tendido a acentuar la desigualdad de las sociedades latinoamericanas. Se impone así alcanzar un nuevo Pacto Fiscal (CEPAL, 1998), en que se definan las prioridades de política y las fuentes de financiamiento para llevarlas a cabo, con un peso creciente de la ciudadanía en el proceso de decisión a través de las instituciones democráticas.

\section{VI}

\section{Reflexiones finales}

La crisis de 2008 y las señales de recuperación que han surgido recientemente dejan lecciones importantes para América Latina y el Caribe, no solo en términos de la mitigación en el corto plazo de los efectos de la crisis, sino de la vulnerabilidad de largo plazo del patrón predominante de crecimiento. Aún permanecen viejas brechas que han actuado como barreras al crecimiento con equidad (las brechas de igualdad, productividad, inversión y equilibrio fiscal), y a ellas se agregan las demandas cada vez más urgentes del medio ambiente y del cambio climático. La persistencia de las antiguas brechas y la aparición de nuevas sugieren con toda nitidez que las respuestas de política ofrecidas históricamente por la región no han sido suficientes para impulsar el desarrollo.

A esta comprobación se agrega el hecho de que la postcrisis no se delinea con los mismos trazos del pasado. Si bien es posible que hacia finales de 2009 la región haya recuperado su ritmo de expansión, estimándose para 2010 un crecimiento regional del 4,1\%, ella enfrentará un contexto diferente. Durante 2010 comenzarán a hacerse cada vez más evidentes aquellos elementos que según algunos conformarían lo que se ha comenzado a llamar la "nueva normalidad" en la economía mundial, es decir: menores tasas de crecimiento económico mundial; nuevo papel de las economías emergentes; desaceleración de los flujos comerciales; mayor proteccionismo financiero; conformación de una nueva arquitectura financiera global; y tránsito hacia economías con menores emisiones de $\mathrm{CO}_{2}$. Esta nueva realidad torna incluso menos adecuadas las viejas respuestas de política - tanto aquellas de excesivo proteccionismo como las de liberalización ingenua-y refuerza la necesidad de una nueva reflexión.

En este trabajo se ha entendido que la tradición estructuralista ofrece elementos relevantes para pensar acerca de la crisis y la postcrisis, con énfasis en el papel de las políticas orientadas a la transformación de la estructura productiva y a la difusión del progreso técnico, como un componente central del crecimiento con equidad y sostenibilidad. Este pensamiento cobra incluso mayor validez a la luz de los desafíos climáticos, que implican cambios en las formas de producir y de consumir, y en las formas de generación y uso de energía, que hacen de la huella del carbono una variable principal en la competitividad de los países. Las políticas de adaptación y de reducción del contenido de emisiones requieren de una planificación de largo plazo. Más aún, la nueva normalidad económica ambiental introducirá límites a las emisiones, incentivos, penalizaciones o impuestos en favor de la reducción del carbono, permisos comercializables de emisiones, e incluso se aplicarán regulaciones 
al comercio basadas en el contenido de carbono de las mercancías exportadas ("huella de carbono").

Todo ese complejo desafío de la transformación estructural no podría enfrentarse exclusivamente a partir de los mecanismos automáticos del mercado. Este generará además nuevas tensiones y conflictos en los ámbitos social y político que exigen una reflexión más allá de lo puramente económico. En consecuencia, es natural esperar que la política retorne como protagonista principal en la construcción del futuro.

Esto significa, en primer lugar, retomar la idea de "largo plazo" con el objetivo de la igualdad mediante un enfoque de derechos y ciudadanía, para llegar a una sociedad de bienestar. Los problemas de corto plazo de la crisis deben ser resueltos con la mirada puesta en el largo plazo, desarrollando la capacidad de proponer e implementar políticas públicas que hagan coherentes los distintos horizontes temporales. El futuro se construye con ideas, con liderazgos claros, con visiones estratégicas de largo plazo, pero también - y ello es esencial—con grandes acuerdos políticos y sociales que hagan viables los caminos al desarrollo y den gobernabilidad democrática a los países de la región. Es imprescindible contar con una visión estratégica de largo plazo gestionada por la voluntad soberana y por la vía de las instituciones de la democracia. Estos son ingredientes inherentes al propio concepto de desarrollo.

En segundo lugar, con la centralidad de la política se vuelve más urgente reflexionar sobre las nuevas funciones que el Estado debe desempeñar para dar solidez a los anhelos de desarrollo de la ciudadanía. Durante mucho tiempo se supuso que la provisión de los bienes públicos podría ser asegurada por el mercado libre de intervención, pero crecientemente se reconoce que ello no es así. El Estado es el locus de la acción política y su papel debe ser redefinido para que brinde la garantía de la oferta de esos bienes. Se requiere un nuevo equilibrio entre Estado, mercado y ciudadano, $\mathrm{y}$, por ende, la creación y reinvención de instituciones públicas, privadas, solidarias y comunitarias. Ello, a su vez, exige el desarrollo de mejores esquemas de organización y evaluación de gestión pública para lograr la rendición de cuentas y la transparencia. Retomar lo público como el espacio de lo colectivo, del hacer de todos los ciudadanos y no solo del gobierno o el Estado, es imprescindible para la inclusión y el pleno ejercicio de la ciudadanía y, desde ahí, para la definición de las prioridades nacionales.

Detrás de toda esta tarea subyace, en tercer lugar, la construcción de un "Pacto Fiscal" sólido, que determine una estructura más progresiva de los impuestos y haga viable el financiamiento de las políticas. Los distintos objetivos propuestos y el papel más amplio de las políticas no podrían alcanzarse sin la construcción de acuerdos políticos —explícitos o implícitos-acerca del nivel, composición y tendencia del gasto público y de su financiamiento.

El conjunto de los puntos anteriores converge en cuanto a la necesidad de diseñar una "nueva arquitectura estatal", que permita al Estado volver a desempeñar un papel relevante en el bienestar general y en la conducción de las estrategias de desarrollo de los países latinoamericanos, superando el paradigma de su "subsidiariedad" al mercado. Se propone que, a partir de una mirada crítica sobre su desempeño histórico, se redefina el papel del Estado con propuestas para dotarlo de las herramientas suficientes, de modo que encuentre su lugar preciso en equilibrio con el mercado y con los derechos ciudadanos — no solo los de esta generación, sino también los de generaciones futuras - que habrán de heredar un equilibrio ambiental cada vez más precario.

En resumen, si bien no hay modelos únicos y cada sociedad deberá reflexionar y a la postre acordar ese balance según su dinámica de desarrollo, todos coinciden en que el Estado deberá tener un papel más significativo y protagónico en garantizar bienes públicos, dinamizar el crecimiento, alcanzar la estabilidad económica, promover una reforma fiscal que sea equitativa, fomentar la necesaria convergencia productiva con innovación, y generar consensos en torno de pactos fiscales con claro efecto redistributivo. Es en el marco de ese estado de bienestar, y no meramente subsidiario, que será posible relanzar los objetivos del desarrollo en las nuevas condiciones y reglas que se están definiendo en la economía internacional postcrisis. 
CEPAL (Comisión Económica para América Latina y el Caribe) (2009a), Balance preliminar de las economías de América Latina y el Caribe 2009 (LC/G.2424-P), Santiago de Chile, diciembre. Publicación de las Naciones Unidas, $\mathrm{N}^{\circ}$ de venta: S.09.II.G.149.

(2009b), El comercio internacional en América Latina y el Caribe en 2009: crisis y recuperación (LC/L.3184-P), Santiago de Chile, diciembre.

(2009c), La economía del cambio climático en América Latina y el Caribe. Síntesis 2009 (LC/G.2425), Santiago de Chile, noviembre.

(2009d), Panorama social de América Latina 2009 (LC/G.2423-P), Santiago de Chile, noviembre.

(2009e), La reacción de los gobiernos de las Américas frente a la crisis internacional: una presentación sintética de las medidas de política anunciadas hasta el 30 de septiembre de 2009 (LC/L.3025/Rev.5), Santiago de Chile, octubre.

(2009f), Panorama de la inserción internacional de América Latina y el Caribe: crisis y espacios de cooperación regional (LC/G.2413-P), Santiago de Chile, agosto. Publicación de las Naciones Unidas, $\mathrm{N}^{\circ}$ de venta: S.09.II.G.62.

(2009g), Estudio económico de América Latina y el Caribe 2008-2009 (LC/G.2410-P), Santiago de Chile, julio. Publicación de las Naciones Unidas, $\mathrm{N}^{\mathbf{0}}$ de venta: S.09.II.G.2.

(2009h), La inversión extranjera directa en América Latina y el Caribe 2008 (LC/G.2406-P), Santiago de Chile, mayo. Publicación de las Naciones Unidas, $\mathrm{N}^{\circ}$ de venta: S.09.II.G.24.

(2008a), La transformación productiva 20 años después: viejos problemas, nuevas oportunidades (LC/G.2367(SES.32/3)), Santiago de Chile, mayo.

(2008b), Estudio económico de América Latina y el Caribe 2007-2008 (LC/G.2386-P), Santiago de Chile, agosto. Publicación de las Naciones Unidas, $\mathrm{N}^{\circ}$ de venta: S.08.II.G.2.

(2007), Progreso técnico y cambio estructural en América Latina (LC/W.136), Santiago de Chile, octubre.

(2006), La protección social de cara al futuro: acceso, financiamiento y solidaridad (LC/G.2294(SES.31/3)), Santiago de Chile, marzo.

(2002), Globalización y desarrollo (LC/G.2157(SES.29/3)), Santiago de Chile, mayo.

(1998), El pacto fiscal: fortalezas, debilidades, desafíos (LC/G.1997/Rev.1-P), Santiago de Chile, mayo. Publicación de las Naciones Unidas, $\mathrm{N}^{\circ}$ de venta: S.98.II.G.5.

Cimoli, Mario y Gabriel Porcile (2008), "Volatility and Crisis in Catching-up Economies: Industrial Path-Through under the Stickiness of Technological Capabilities and the 'Red Queen Effect'", documento presentado en la Conferencia sobre economía del desarrollo (Mount Holyoke College, Springfield, Massachusetts, noviembre de 2008).

DESA (Departamento de Asuntos Económicos y Sociales) (2010), Situación y perspectivas para la economía mundial 2010, Nueva York, Naciones Unidas, diciembre.

Fajnzylber, Fernando (1990), "Industrialización en América Latina: de la "caja negra' al "casillero vacío", serie Cuadernos de la CEPAL, No 60 (LC/G.1534/Rev.1-P), Santiago de Chile. Publicación de las Naciones Unidas, $N^{\circ}$ de venta: 89.II.G.5
Ffrench-Davis, Ricardo (2005), Reforming LatinAmerica's Economies: After Market Fundamentalism, Nueva York, Palgrave Macmillan.

FMI (Fondo Monetario Internacional) (2009), Perspectivas de la economía mundial, 2009, Washington, D.C., octubre.

Hopenhayn, Martín (2001), "Viejas y nuevas formas de la ciudadanía", Revista de la CEPAL, $\mathrm{N}^{\circ} 73$ (LC/G.2130-P), Santiago de Chile, abril.

IFI (Instituto de Finanzas Internacionales) (2009), Capital Flows to Emerging Markets, Washington, D.C., octubre.

Infante B., Ricardo y Osvaldo Sunkel (2009), "Chile: hacia un desarrollo inclusivo", Revista de la CEPAL, N 97 (LC/G.2400-P), Santiago de Chile, abril.

Kacef, Osvaldo y Juan Pablo Jiménez (comps.) (2009), Políticas macroeconómicas en tiempos de crisis: opciones y perspectivas (LC/W.275), Santiago de Chile, agosto.

Martner, Ricardo (2007), "La política fiscal en tiempos de bonanza", serie Gestión pública, N ${ }^{\circ} 66$ (LC/L.2736-P), Santiago de Chile, Instituto Latinoamericano y del Caribe de Planificación Económica y Social (ILPES), mayo. Publicación de las Naciones Unidas, $\mathrm{N}^{\mathrm{o}}$ de venta: S.07.II.G.74.

McKinsey Global Institute (2009), Global Capital Markets: Entering a New Era, McKinsey\&Company, Nueva York, septiembre.

Ocampo, José Antonio (comp.) (2005), Beyond Reforms: Structural Dynamics and Macroeconomic Vulnerability, Washington, D.C., Stanford University Press/Banco Mundial.

OCDE (Organización de Cooperación y Desarrollo Económicos) (2009), OECD Economic Outlook, № 86, París, noviembre.

oMC (Organización Mundial del Comercio) (2009), Informe sobre el comercio mundial 2009, Ginebra, julio.

Orozco, Manuel (2009), Understanding the Continuing Effect of the Economic Crisis on Remittances to Latin America and the Caribbean, Washington, D.C., Banco Interamericano de Desarrollo, agosto.

Pineda, Ramón, Esteban Pérez-Caldentey y Daniel Titelman (2009), "The current financial crisis: old wine in new goatskins or is this time different for Latin America?", Santiago de Chile, Comisión Económica para América Latina y el Caribe (CEPAL), marzo, inédito.

Prebisch, Raúl (1949), El desarrollo económico de América Latina y algunos de sus principales problemas (E/CN.12/89), Santiago de Chile, Comisión Económica para América Latina y el Caribe (CEPAL).

Rosales, Osvaldo (2009), "La globalización y los nuevos escenarios del comercio internacional", Revista de la CEPAL, $\mathrm{N}^{\circ} 97$ (LC/G.2400-P), Santiago de Chile, octubre.

Samaniego, Joseluis (coord.) (2009), Cambio climático y desarrollo en América Latina y el Caribe: una reseña (LC/W.232), Santiago de Chile, noviembre.

Sojo, Ana (ed.) (2009), "Hacia la universalidad, con solidaridad y eficiencia: el financiamiento de la protección social en países pobres y desiguales", serie Seminarios y conferencias, $\mathrm{N}^{\circ} 55$ (LC/L.3034-P), Santiago de Chile, Comisión Económica para América Latina y el Caribe (CEPAL), mayo. Publicación de las Naciones Unidas, $\mathrm{N}^{\circ}$ de venta: S.09.II.G.39.

Stiglitz, Joseph y otros (2006), Stability with Growth: Macroeconomics, Liberalization, and Development, Oxford, Oxford University Press, octubre. 